Hispania Sacra, Legalidad y conflictos, 58 117, enero-junio 2006, 223-260, ISSN: 0018-215-X

\title{
EL CLERO CONTESTATARIO DE FINALES DEL FRANQUISMO. EL CASO FABARA
}

\author{
POR \\ Pablo Martín de Santa Olalla Saludes \\ Doctor en Historia Contemporánea. Universidad Autónoma de Madrid
}

\begin{abstract}
RESUMEN
El Concilio Vaticano II (1962-1965) supuso un extraordinario cambio en muchos aspectos de la fe católica, entre los que debe incluirse el concepto de Iglesia. Un sector del clero consideró que era el momento de romper con las rígidas estructuras de la institución, basadas en la importancia de la jerarquía y el orden, lo que supuso un inevitable conflicto con las diferentes autoridades eclesiales. En el caso de España, este problema adquirió mayor complejidad todavía en la medida que los cambios en el seno de la Iglesia fueron confundidos, en no pocas ocasiones, con los objetivos de democratizar una sociedad que hasta ese momento se encontraba bajo el autoritarismo del Régimen de Franco.
\end{abstract}

PALABRAS CLAVE: Concilio, catolicismo, diocesis, clero.

\section{ABSTRACT}

Council Vatican II (1962-1965) supposed a very important change in many aspects of catholic faith, included the concept of Church. A part of clergy considered that it was the moment to break with the rigid structures of this institution, based in the importance of hierarchy and order, and it meant an unavoidable conflict with the different ecclesial authorities. In the case of Spain, this problem turned bigger because of the confusion of changes in Catholic Church with the targets for democratization of a society that was under authoritism of Franco's Regime.

KEY WORDS: Council, Catholicism, dioceses, clergy. 
Uno de los fenómenos más destacados de la Iglesia Católica española durante el Posconcilio fue, ciertamente, el de la existencia de un clero que, por el alto grado de rebeldía que manifestaron hacia sus superiores jerárquicos, fue denominado «contestatario». Este hecho, que se puede decir que era totalmente novedoso en la Historia de la Iglesia española a lo largo del siglo XX, no poseía una sola explicación, sino varias. Entre ellas debemos citar: la existencia de un importante número de sacerdotes que realmente no eran vocacionales de su condición, sino que se encontraban dentro del clero por una necesidad de subsistencia en un país que había pasado por un subdesarrollo muy acusado; la ausencia de una auténtica modernización de la Iglesia española, muy atrasada teológicamente con respecto al resto de las Iglesias europeas; y la ubicación dentro de un régimen dictatorial, que hacía muchas veces convertir las predicaciones en una pura y dura lucha política.

Este artículo no pretende ofrecer una investigación exhaustiva sobre un fenómeno que posee una extraordinaria amplitud, sino tan solo centrarse en un caso concreto que, no obstante, tuvo gran relevancia. Nos estamos refiriendo al llamado caso Fabara, que tuvo lugar en la primavera-verano de 1974 dentro de la archidiócesis de Zaragoza, y que provocó una importante división de opiniones por las polémicas medidas tomadas por el titular de dicha diócesis, el palentino Pedro Cantero Cuadrado. Con ello podremos adentrarnos en un mundo, el de la contestación dentro del clero, que constituyó una auténtica fuente de problemas para muchos obispos del Posconcilio, prelados que no entendían algo que ellos, durante su etapa como sacerdotes, no habían vivido y, a lo que, en la mayor parte de los casos, no supieron cómo hacer frente.

\section{APROXIMACIÓN A UNA REALIDAD ECLESIAL}

Zaragoza, parece difícil ponerlo en cuestión, es una de las principales diócesis del país. Aunque no es sede «cardenalicia», en el sentido de que sus sucesivos obispos residenciales nunca han sido elevados al cardenalato, posee el rango de archidiócesis (y, además, desde hace mucho, concretamente desde 1318) $\mathrm{y}$, por tanto, se encuentra entre los diez grandes obispados de España, algo por otra parte lógico teniendo en cuenta que es una de las principales ciudades del país. Los últimos «inquilinos» de Zaragoza han sido todos ellos personalidades de relevancia en la Iglesia española: Casimiro Morcillo (septiembre de 1955marzo de 1964); Pedro Cantero (mayo de 1964-junio de 1977); y Elías Yanes (junio de 1977-abril de 2005). El primero llegaría a la presidencia de la Conferencia Episcopal, mientras el tercero sería Secretario General de la misma y asesor de la Nunciatura durante la etapa de Luigi Dadaglio (1967-1980). Así que, cuando Cantero llegó a Zaragoza, se encontró al frente de una diócesis con

Hispania Sacra, Legalidad y conflictos, 58

117, enero-junio 2006, 223-260, ISSN: 0018-215-X 
más de medio millón de fieles, prácticamente el $100 \%$ de la población de la zona.

Por otra parte, el nuevo Arzobispo de Zaragoza era un hombre con un notable grado de identificación con el Régimen de Franco. Diez años más joven que el Caudillo, había vivido como sacerdote la persecución religiosa durante la Guerra Civil y probablemente ello debió marcar su posterior actuación. No obstante, hay que decir que no había llegado al episcopado especialmente joven, pues los casi cincuenta años con los que fue nombrado Obispo de Barbastro se encontraban bastante lejos de, por ejemplo, los treinta y ocho que tenía Tarancón cuando seis años antes fue designado para la diócesis de Solsona. Su paso por Barbastro sería bastante fugaz, ya que estuvo menos de dos años, hasta que en octubre de 1953 la Santa Sede decidió ponerle al frente de la recién creada diócesis de Huelva. Había sido precisamente en ese año cuando Cantero publicara la obra que mejor manifestaría su pensamiento, un pequeño manuscrito titulado En defensa de la unidad católica de España ${ }^{1}$. Y es que Cantero era, ciertamente, un firme opositor de la libertad religiosa y así lo manifestaría durante la celebración del Concilio Vaticano II $^{2}$.

\section{EL CASO FABARA}

Resulta difícil saber cuándo se inició realmente lo que conoceríamos como caso Fabara. Da la impresión de que el conflicto en sí tuvo su punto de partida el 14 de junio de 1974, cuando Pedro Cantero envió una carta a Wirberto Delso Díez, en ese momento Párroco de Fabara ${ }^{3}$. En ella le comunicaba el cese en su cargo (que pasaba de manera provisional a quien en era Coadjutor de la misma, Leoncio Pablo Figueras) y le señalaba «pastoralmente necesario» el que se dedicara durante algún tiempo a la oración, el estudio y la reflexión de la Teología y Pastoral, «en la forma de que de común acuerdo se estime más procedente». Las razones que daba para dicha decisión eran bastante amplias, aunque algunas de ellas no suficientemente concretas:

«En vista de los informes que, por diversos y autorizados conductos, han llegado a este Arzobispado acerca de la situación religiosa y moral de la feligresía de la Parroquia de

\footnotetext{
1 Sería publicado en Madrid, Consejo Superior de Investigaciones Científicas.

2 Véase al respecto P. MARTín DE SANTA Olalla SAludes, La Iglesia que se enfrentó a Franco. Pablo VI, la Conferencia Episcopal y el Concordato de 1953, Madrid, Dilex, 2005, pp. 85 y 86.

${ }^{3}$ Los únicos datos que tenemos Delso son los que proporcionaría su arzobispo Pedro Cantero en un informe enviado a Roma. Según este, Wirberto Delso Díez había nacido el 13 de agosto de 1935 y había sido ordenado sacerdote el 17 de mayo de 1963. El 30 de mayo de 1968 Cantero había decidido nombrarle Párroco de Fabara, una localidad de 1666 habitantes en la que permanecería hasta el momento del conflicto.
} 
Fabara; comprobados con motivo de la Santa Visita Pastoral a dicha Parroquia; teniendo en cuenta que la mencionada situación de la feligresía de Fabara obedece en gran medida a las ideas, actitudes y hasta el léxico de $\mathrm{Vd}$. en el desempeño de su cargo pastoral de Ecónomo de la citada Parroquia de Fabara; en conformidad con las directrices del Concilio Ecuménico Vaticano II y en uso de mis facultades como Pastor de esta Archidiócesis de Zaragoza, desde las consultas y asesoramientos convenientes...» ${ }^{4}$.

¿Quién había escrito esos informes? ¿Cuáles eran esas «ideas», «actitudes» y «léxico» utilizados por este sacerdote»? ¿Con qué consultas y asesoramientos «convenientes» había contado Cantero?

Pues, fueran cuales fueran las razones que llevaron a Cantero a cesar a Delso Díez, lo cierto es que el sacerdote no tardó en sentirse respaldado por sus fieles. Por tanto, lo que suponía una cuestión meramente de orden jerárquico se tornaba en un conflicto diocesano en toda su envergadura. Así, la Asamblea Parroquial se dirigía el 22 de junio a Cantero

«(...) para pedirle, por favor, nos explique claramente los motivos por los cuales ha de cesar de su cargo en esta parroquia, pues necesitamos saber con precisión si las acusaciones que se le atañen son graves, y conocer exactamente lo referente a las ideas, actitudes y léxico, palabras estas un tanto confusas, y más para nosotros los abajo firmantes que estamos totalmente de acuerdo con la doctrina y con cada una de las maneras de proceder de nuestro querido pastor parroquial.

Mientras tanto no hayamos entendido que es justa la decisión por Vd. tomada queremos seguir con nuestro buen Pastor mientras Dios no disponga otra cosa ${ }^{5}$.

En realidad, todo el asunto se había desatado mes y medio antes, cuando tuvo lugar la celebración de un cursillo de la Acción Católica general. El lugar escogido para dicha celebración había sido la propia Fabara, siendo las fechas los días 4 y 5 de mayo de 1974. Dicho cursillo había sido solicitado por los militantes del centro de Acción Católica de Fabara y había contado, además, con la autorización del propio Wirberto Delso.

No sabemos si, por orden del propio Pedro Cantero o no, pero lo cierto es que el cursillo ${ }^{6}$ estuvo controlado por las autoridades diocesanas, ya que al mismo asistieron no sólo dos miembros de la Asociación Católica Nacional de Propagandistas (Jesús Casas y Vicente Cuesta), sino también el propio Consiliario diocesano, Jesús Imaz. Dicho cursillo constituiría el punto de partida de todo el proceso, aunque da la impresión de que hacía tiempo que Cantero sospechaba de las actuaciones del Párroco de Fabara.

\footnotetext{
4 Archivo de la Embajada de España cerca de la Santa Sede (AEESS) R237 bis. Carta del Arzobispo de Zaragoza al Rvdo. Sr. D. Wirberto Delso Díez. Zaragoza, 14 de junio de 1977.

5 AEESS R237 bis. Carta de la Asamblea Parroquial de Fabara al Arzobispo de Zaragoza. Fabara, 22 de junio de 1974.

6 Al que, por cierto, tan sólo asistirían dieciséis personas, doce de ellas pertenecientes al pueblo de Fabara y cuatro a la vecina localidad de Nonaspe.

Hispania Sacra, Legalidad y conflictos, 58

117, enero-junio 2006, 223-260, ISSN: 0018-215-X
} 
Los miembros de la delegación diocesana informaron primero de manera verbal al Arzobispo de Zaragoza, pero éste les pediría un informe por escrito cuando ya el asunto comenzaba a cobrar especial virulencia. Así, el 18 de octubre de 1974 Imaz y Jesús García Artal, Presidente de la Junta diocesana de hombres de Acción Católica, confirmaban a Cantero que en el cursillo de mayo de 1974 habían detectado una «división muy fuerte» entre los asistentes al mismo, lo que, a su juicio, tenía su razón de ser en la «diversidad de opinión frente al Párroco». Parecían innegables las «quejas» sobre «la actuación pastoral» de Wirberto Delso, y además esas quejas se centraban en hasta seis puntos diferentes: «respecto a la Misa Dominical, fundamentalmente homilías, habiendo llegado los padres a prohibir a sus hijos la asistencia a la Misa; respecto a la moral en las relaciones prematrimoniales, incluso en las catequistas; respecto a la predicación de la justicia, dando un sentido de marcada tendencia marxista; por la no aceptación de la Acción Católica, llegando hasta el desprecio de los militantes, a los que pretende lanzar con riesgo no adecuado en los compromisos de orden temporal; respecto a la distribución de sacramentos, especialmente a los enfermos, mostrando una inhibición total; por inculcar a los jóvenes la rebeldía frente a la estructura familiar por un desviado sentido de la libertad»?

Dichos dirigentes diocesanos afirmaban haber hablado con los militantes de la Acción Católica de Fabara para que estos dialogaran con el párroco con el fin de «salvar al menos el escándalo» que la ruptura entre ambos estaba provocando. Al mismo tiempo, informaban a Pedro Cantero de que Wirberto Delso no sólo se había mostrado «indiferente y con un mutismo total» frente a las acusaciones vertidas hacia él por los asistentes al cursillo, sino que incluso había llegado a afirmar que sólo tendría en cuenta los planes pastorales de la Acción Católica en la medida que estos coincidieran con los suyos propios.

La dura contestación de Delso al cese decretado por Cantero fue respondida de manera inmediata por el propio Arzobispo de Zaragoza. En efecto, el 29 de junio el prelado palentino escribía a su sacerdote y le rebatía uno por uno todos los puntos de la carta escrita por Delso. Respecto a esa idea de que le había cesado a partir de supuestas «generalidades» y «acusaciones totalmente falsas y gratuitas», le recordaba que lo hacía en virtud del descontento sembrado entre la feligresía, descontento que él mismo había comprobado en persona durante su visita pastoral a Fabara. No había sido él quien había dado notoriedad al cese del Párroco de Fabara, sino que lo había hecho el damnificado por la medida, esto es, el propio Delso. Además, el Párroco de Fabara había mostrado durante

${ }^{7}$ AEESS R237 bis. Informe que presenta al Excmo. Y Rvdmo. Sr. Dr. Don Pedro Cantero Cuadrado, Arzobispo de Zaragoza, el Presidente de la Comisión Diocesana de los Hombres de la Acción Católica General de Zaragoza, Don Jesús García Artal, con relación al Cursillo de Acción Católica General celebrado en Fabara. Zaragoza, 18 de octubre de 1974. 
su entrevista con el Vicario de Pastoral para los Pueblos nula predisposición a un entendimiento. Cantero no podía ser más claro:

«En esta ocasión, como en otras muchas, su actitud ha sido de desprecio y autosuficiencia con respecto a las autoridades diocesanas. Esta postura hace imposible un diálogo sincero y constructivo.

Me habla Vd. de la conveniencia de la celebración de un "juicio eclesiástico público, donde la acusación sea pública y la defensa también". No es este el camino ni legal ni pastoral. Por otra parte, Vd. oyó las acusaciones contra su actuación pastoral y la de algunos catequistas en la Asamblea Parroquial celebrada con mi presencia, con ocasión de la Santa Visita Pastoral, a la que asistió gran parte de la Comunidad Parroquial. Vd. pudo defenderse públicamente, y no pronunció ni una sola palabra, viéndome yo obligado a adoptar una actitud conciliadora, para salvar una situación comprometida para $\mathrm{Vd}$.

(...) Mi conciencia pastoral me obliga a actuar siempre con la caridad y mansedumbre cristianas, pero también me obliga a velar por el bien espiritual de todas las almas, por la paz y por la unidad en todas las comunidades diocesanas» ${ }^{8}$.

\section{LA CONVERSIÓN DE UN PROBLEMA PARROQUIAL EN UN CONFLICTO DIOCESANO}

Desconocemos si esto era lo que Cantero podía esperar, pero lo cierto es que el cese de Delso desató una auténtica ola de solidaridad entre una parte significativa del clero de la archidiócesis de Zaragoza. En efecto, el 5 de julio de 1974 se pondría de manifiesto que el Párroco de Fabara no era el único que se sentía alejado de su prelado, sino también un buen número de sus sacerdotes. Tres sacerdotes ${ }^{9}$ serían los primeros en mostrar su abierta discrepancia con el arzobis-

\footnotetext{
${ }^{8}$ AEESS R237 bis. Carta del Arzobispo de Zaragoza al Párroco de Fabara. Zaragoza, 29 de junio de 1974.

9 Javier Uranga, Jesús Gil García y Farmulo Martínez. Por cierto que Jesús Gil García hacía tiempo ya que se encontraba en la «lista negra» no sólo de la archidiócesis de Zaragoza, sino también de la propia Santa Sede. De hecho, casi cuatro años antes el Nuncio Dadaglio había escrito a Cantero informándole de que la Secretaría de Estado vaticana le había hecho el «venerado encargo» y «con carácter secreto», de evitar que este sacerdote pudiera retornar a Bolivia (situación extensible a otros tres sacerdotes cuyo nombre y diócesis a la que pertenecían se desconoce, aunque sí sabe que pertenecían a OCSHA, Obra de Cooperación Sacerdotal Hispanoamericana), donde había estado trabajando en los últimos tiempos (concretamente en el Seminario Mayor de Cochabamba), debido «al clima de malestar» que allí había creado. Véase al respecto AEESS R237 bis. Carta del Nuncio en España al Arzobispo de Zaragoza. Madrid, 4 de noviembre de 1970. Casi un año después, Dante Pasquinelli, ayudante de Dadaglio, confirmaba a Pedro Cantero la disposición de la Santa Sede sobre este sacerdote. AEESS R237 bis. Carta del Encargado de Negocios de la Nunciatura al Arzobispo de Zaragoza. Madrid, 26 de octubre de 1971. Finalmente, en noviembre de 1971 Pasquinelli volvía a escribir a Cantero para decirle que «mucho» agradecía al Arzobispo de Zaragoza «(...) el empeño que ha puesto en solucionar este asunto que tan maravillosamente ha conseguido, con su acertada prudencia, llevar a término satisfactorio para todos». AEESS R237 bis. Carta del Encargado de Negocios a.i. de la Nunciatura al Arzobispo de Zaragoza. Madrid, 26 de noviembre de 1971.
}

Hispania Sacra, Legalidad y conflictos, 58

117, enero-junio 2006, 223-260, ISSN: 0018-215-X 
po, y lo harían de manera extraordinariamente dura, al afirmar que la destitución de Delso no era más que un hecho más

«(...) dentro de la historia de su actuación pastoral en Zaragoza, que refleja su autoritarismo expresado fundamentalmente para ahogar, poco a poco, a un sector de la Iglesia Diocesana que trata de comprometerse en la liberación de los oprimidos.

Dentro de este sector de la Iglesia se encuentra la Comunidad de Fabara, como pudimos comprobar muchos de nosotros el pasado 29 de junio» ${ }^{10}$.

Así, estos sacerdotes se solidarizaban con el Párroco de Fabara y, por ello, presentaban a Cantero la dimisión de sus respectivos cargos pastorales en un plazo de quince días, a no ser que antes de ello fuera revocado el cese de Delso, lo que les llevaría a continuar en sus puestos. En otras palabras, estos sacerdotes estaban dando un ultimátum en toda regla al Arzobispo de Zaragoza.

Luego hemos sabido, por una respuesta de Cantero que tuvo lugar tan sólo un día después de recibir esa carta, que en realidad estos tres sacerdotes representaban a un grupo mucho más amplio: en concreto, a un total de veinticuatro clérigos. El Arzobispo de Zaragoza mostró una actitud de total firmeza ante este conato de rebeldía y se limitó a explicar las razones ${ }^{11}$ del cese del Párroco de Fabara:

«Pude comprobar una profunda división y excitación de la feligresía en relación con los criterios y la actuación de D. Gilberto: unas denuncias concretas sobre desviaciones doctrinales en la formación catequética y en la educación de la fe del Pueblo de Dios; un desmantelamiento de las Asociaciones Parroquiales de piedad y apostolado; una notable disminución en el cumplimiento de los deberes y prácticas piadosas. Estas acusaciones concretas fueron escuchadas por el mismo D.Wirberto, el cual pudo entonces defenderse $\mathrm{y}$, sin embargo, no pronunció una sola palabra, viéndome yo obligado a adoptar una actitud conciliadora para salvar una situación comprometida para él» ${ }^{12}$.

Es más, a través de su Vicario de Pastoral para los Pueblos había podido comprobar la actitud de Wirberto Delso de «permanente rotura del diálogo con las Autoridades y Vida Diocesana», y que él mismo no se había «(...) recatado en manifestar constante y públicamente» ${ }^{13}$.

10 AEESS R237 bis. Carta de tres sacerdotes al Arzobispo de Zaragoza. Zaragoza, 5 de julio de 1974.

${ }^{11}$ El prelado confirmaba que las informaciones sobre la actuación de Delso le habían llegado a través de varios sacerdotes, de militantes de la Acción Católica diocesana y de algunos dirigentes diocesanos de movimientos apostólicos, lo que nos habla de una fuerte división en el seno de la archidiócesis de Zaragoza.

12 AEESS R237 bis. Carta del Arzobispo de Zaragoza a uno de los sacerdotes de la diócesis de Zaragoza, en representación del grupo de dimisionarios. Zaragoza, 6 de julio de 1974.

13 Ibidem. 
¿Y esa acusación de que el Arzobispo de Zaragoza no trabajaba a favor de la liberación de los oprimidos? La respuesta de Cantero, en ese sentido, más que contundente, lo que se encontraba marcada era por la ironía, por no decir directamente la burla:

\begin{abstract}
«El Obispo siempre, y especialmente al hacer la Santa Visita Pastoral, tiene la misión de liberar a los oprimidos del error, y por todo pecado; y dentro de esta misión de servicio espiritual al Pueblo de Dios, y siguiendo el espíritu y los métodos del Evangelio, hacer cuanto pueda por la liberación integral de todos nuestros hermanos.

En este sentido y con esta finalidad no he dudado en mantener mi apoyo moral y económico a los sacerdotes diocesanos que, dentro de las normas diocesanas, han manifestado sus deseos de dedicarse al servicio del mundo del trabajo» ${ }^{14}$.
\end{abstract}

Así, parece evidente que el Arzobispo de Zaragoza estaba dispuesto a admitir la dimisión de este sector rebelde del clero diocesano, si bien esperaba que reconsideraran su ultimátum. Cantero no sólo no mostraba el más mínimo signo de amedrentamiento, sino que incluso que pasaba al terreno de la ofensiva al advertir de que, si se persistía en esa actitud de subversión, aceptaría la dimisión

«(...) con todas las consecuencias y me veré obligado a informar a la Diócesis de hechos ocurridos y de otros documentos que la prudencia y la caridad me han obligado a silenciar hasta el presente» ${ }^{15}$.

Seguramente lo más importante para Pedro Cantero era que el apoyo dentro de la jerarquía diocesana a su actuación en este tema era casi total. En efecto, en la mañana del 15 de julio tuvo lugar una reunión el Consejo Presbiteral a la que asistieron veinte clérigos. Se sometieron a deliberación tres preguntas concre$\operatorname{tas}^{16}$, siendo el resultado final de la votación (que tuvo carácter secreto) una demostración masiva de solidaridad con Pedro Cantero. Sólo en la tercera de las preguntas hubo una persona que discrepó, y lo hizo con un «no» entre interrogaciones. De esta manera, el Consejo Presbiteral consideraba necesario mantener el cese; afirmaba no tener justificación la actuación del grupo de sacerdotes que se había solidarizado con Wirberto Delso; y pensaban que, en el caso de mantenerse la actitud de rebeldía de este grupo, debía aceptárseles la dimisión.

Sólo un día después, y probablemente sin saber la respuesta del Consejo Presbiteral (salvo que hubiera relación entre unos y otros), el grupo de sacerdo-

\footnotetext{
14 Ibidem.

15 Ibidem.

16 Fueron las siguientes: «Cree Vd. que ha de mantenerse el cese dado a D. Wirberto por el Sr. Arzobispo?» (1); «¿Encuentra Vd. justificada la actitud de solidaridad que han expresado 24 sacerdotes con D. Wirberto, y la notoriedad que han dado en Asambleas, Homilías y prensa?» (2); y «En el caso en que los 24 sacerdotes persistan en su actitud de dimitir de sus puestos pastorales, cree que el Sr. Arzobispo ha de aceptarles la dimisión?» (3). Ibidem.

Hispania Sacra, Legalidad y conflictos, 58

117, enero-junio 2006, 223-260, ISSN: 0018-215-X
} 
tes «rebeldes» escribió una nueva carta con destino el arzobispado de Zaragoza. En ella estos clérigos informaban a Cantero de que los días 12 y 13 de ese mes se habían reunido con el Nuncio Dadaglio en Madrid, y que éste les había indicado la conveniencia de mantener un «diálogo abierto y constructivo» con su arzobispo en torno al llamado caso Fabara, opción que posteriormente había sido debatida por estos sacerdotes en varias asambleas y aceptada de «acuerdo unánime»: en otras palabras, Dadaglio no había querido seguir el principio jerárquico y, en lugar de apoyar rotundamente a Cantero, había optado por una postura de neutralidad e incluso de inhibición ante lo que estaba sucediendo. Además, el Nuncio les había reconocido a estos sacerdotes el derecho a recurrir a la Santa Sede, por lo que avisaban a Cantero de que podían hacer uso de este derecho ${ }^{17}$.

Esta nueva muestra de rebeldía indignó profundamente a Cantero, quien mostró públicamente su respeto por la actitud de la Nunciatura sobre la posibilidad de recurrir a la Santa Sede pero no sobre ese posible diálogo con sus sacerdotes, escudándose en argumentos poco consistentes. El destinatario de dicha carta sería Jesús Molinero, Ecónomo de la Parroquia de San Mateo y la persona que encabezaba la anterior misiva:

«Como Vds. me pedían una contestación a su Escrito del 5 del actual, les di mi respuesta en mi carta del 6. En ella les pedía una respuesta personal a mi carta personal que les dirigí certificada. Vds. parece que tratan de eludir el cumplimiento de este deber y delicadeza fundamental para con su Obispo. Sin el cumplimiento previo de su respuesta personal a mi carta, yo no veo un espíritu sincero de respeto y obediencia a su Prelado, ni voluntad de mantener un diálogo eclesial» ${ }^{18}$.

Precisamente esta ausencia de apoyo de la Nunciatura fue la que hizo a Cantero escribir una segunda carta que tenía precisamente por destinatario el propio Luigi Dadaglio. Para escribir al Nuncio el prelado palentino se tomó más tiempo, consciente de que no podía hablar al enviado de la Santa Sede con la misma contundencia que había empleado con sus sacerdotes. Según informaba el arzobispo, Dante Pasquinelli, Consejero de la Nunciatura (por tanto, «mano derecha» de Dadaglio), le había pedido un informe sobre lo sucedido en relación al

17 Firmaban esta carta los sacerdotes Jesús Molinero, Gregorio Forniés y Mario Cuartero «en representación y por orden de» otros catorce clérigos: Jesús Cabello, Ángel Delgado, Jesús Borao, Manuel Liarte, Francisco Chueca, Victorio Sevilla, Álvaro Lacaste, Rafael Aranda, José Antonio Pueyo, Ángel Nogueras, Carlos Mendi, Luis Bel, José Guarc y José Ignacio Sarasa. Estos sacerdotes pertenecían tanto al clero regular como al clero secular, si bien no se indicaba la condición de cada uno. $A E$ ESS R237 bis. Carta de un grupo de sacerdotes al Arzobispo de Zaragoza. Zaragoza, 16 de julio de 1974.

18 AEESS R237 bis. Carta del Arzobispo de Zaragoza a uno de los sacerdotes de la diócesis de Zaragoza, en representación del grupo de dimisionarios. Zaragoza, 6 de julio de 1974. Carta del Arzobispo de Zaragoza al Ecónomo de la Parroquia de San Mateo. Zaragoza, 18 de julio de 1974. 
llamado caso Fabara y, dado que Pasquinelli iba a estar durante esas semanas de vacaciones en Italia, y ante la gravedad de lo sucedido (Cantero denunciaba que estos sacerdotes habían intentado «intimidarle» con la dimisión de sus respectivos cargos pastorales), había decidido escribir directamente al Nuncio para contarle lo que estaba sucediendo.

Así, Cantero aseguraba haber hecho todo lo posible para que el asunto no alcanzara una dimensión «extraeclesial»; sin embargo, no había sucedido lo mismo por parte del grupo de veinticuatro sacerdotes que se resistían a su autoridad, quienes, según el Arzobispo de Zaragoza, habían organizado multitud de reuniones, habían implicado a varios sacerdotes de fuera de la diócesis (así como a pequeños grupos de fieles) habían visitado a varios obispos de la provincia eclesiástica e incluso habían publicado un artículo «tendencioso» en la publicación diocesana Pueblo de Dios, perteneciente al obispado de Huesca ${ }^{19}$.

El prelado palentino recordó a Dadaglio que los sacerdotes que se habían levantado contra él no suponían ni el $4 \%$ del conjunto del clero. Incluso afirmó que para ese momento algunos ya le habían mostrado su arrepentimiento por haber estampado su firma en el documento donde se amenazaba con la renuncia a los cargos pastorales de que eran responsables de manera respectiva si no se reponía en su cargo a Wirberto Delso.

Consciente de la fama de autoritario que le perseguía, Cantero concluyó su carta al Nuncio con una acendrada defensa de su actuación, en la certeza de que sólo desde el orden y el respeto a la jerarquía, las cosas podrían funcionar dentro de la Iglesia española:

19 Por tanto, hay que suponer que contaban con el apoyo de la entonces máxima autoridad de la diócesis, el navarro Javier Osés, que ejercía como Obispo auxiliar con facultades de residencial ante la invalidez, primero, y fallecimiento, después, del titular de la diócesis, el oscense Lino Rodrigo. Desde luego, Cantero pensaba que Osés estaba detrás de todo lo que había sucedido, y así se lo comentó al Nuncio Dadaglio. Lo hizo de una manera un tanto cínica, exculpando primero a Osés y luego responsabilizándole de lo sucedido: según el Arzobispo de Zaragoza, el «grupo de los 24» andaba «(...) propalando que su actitud es conocida y respaldada por algún Sr. Obispo de esta Provincia Eclesiástica, concretamente por Mons. Javier Osés. Lo mismo se propaló en relación con el caso de Mequinenza ocurrido en Septiembre de 1973.

Es cierto que ellos así lo afirman; es cierto también que el artículo aparecido en la Publicación Oficial del Obispado de Huesca refleja fielmente el pensamiento unilateral del Grupo; pero, por mi parte, debo en conciencia manifestar a Vuestra Excelencia Reverendísima que yo no tengo fundamento objetivo para admitir la veracidad de estas afirmaciones imputadas por personas apasionadas a un venerado Hermano en el Episcopado, miembro además de esta Provincia Eclesiástica.

Lo que aparece público y notorio es la injerencia en asuntos extradiocesanos y la parcialidad por falta de integridad en la exposición de los hechos por parte de la Hoja «Pueblo de Dios», de cuyo contenido es responsable ante la ley civil el propio Prelado a tenor de las normas que regulan en España las publicaciones de la Iglesia». AEESS R237 bis. Carta del Arzobispo de Zaragoza al Nuncio en España. Zaragoza, 21 de julio de 1974. Por cierto, el número exacto donde había salido el artículo era el del 21 de julio de 1974 y se titulaba así: «Nos afecta a todos».

Hispania Sacra, Legalidad y conflictos, 58

117, enero-junio 2006, 223-260, ISSN: 0018-215-X 
«Estas cosas, Señor Nuncio, me hacen sufrir mucho. Dios me ayuda a tener paciencia, a fortalecer mi adhesión inquebrantable a la Santa Iglesia y a nuestro amadísimo Santo Padre. Pero el silencio tiene un límite. No es posible gobernar una Diócesis sin el ejercicio de la autoridad pastoral. Cuando el Pastor hace uso de la autoridad, aún en el momento tan significativo como la Santa Visita Pastoral, lo tachan de autoritarismo o tergiversan la realidad y significación de los hechos, como en parte ellos mismos han reconocido en este caso, en un diálogo que acabo de tener con una representación del Grupo.

En consecuencia, creo que ha llegado el momento de decir: "non possumus" porque en el fondo de las motivaciones e implicaciones del Caso de Fabara se ventila la integridad y la pureza de la fe y de las costumbres, y con actitudes permisivas en este orden de cosas se socaban la moral, la unidad y la disciplina en el Pueblo de Dios» ${ }^{20}$.

Pero la respuesta de Dadaglio a estas palabras no resultó especialmente cálida, o al menos da la impresión de ser más correcta que comprensiva con el Arzobispo de Zaragoza. Lo que en cierto modo resultaba lógico, pues ambos, aún siendo miembros de la Iglesia, militaban en trincheras políticas distintas: mientras Dadaglio apoyaba sin fisuras a Tarancón en el proceso de separación y abierta oposición al Régimen de Franco, Cantero seguía fiel al espíritu del 18 de julio ${ }^{21}$ desde sus diferentes cargos políticos (Consejo del Reino, Consejo de Regencia, etc.). De ahí que la contestación del Nuncio fuera más bien lacónica:

«Estoy convencido de los buenos deseos de Vuestra Excelencia y de sus esfuerzos por solucionar los problemas. Comprendo lo que todo esto tiene que hacerle sufrir. El Episcopado es una pesada carga y en especial en los tiempos presentes, pero el Señor sabrá recompensarle y ayudarle.

Sabe me tiene siempre a su disposición. De Vuestra Excelencia Reverendísima afectísimo en el Señor.

Luigi Dadaglio. N.A. (Nuncio Apostólico)»22.

El 28 de julio el llamado «grupo de los 24» respondía a su obispo y lo hacía de una manera extraordinariamente contundente, yendo punto por punto sobre lo escrito por Cantero: era una respuesta individual que, sin embargo, iba firma-

20 Ibidem.

21 Estas fueron las palabras de Cantero cuando tuvo lugar el fallecimiento del General Franco el 20 de noviembre de 1975: «Franco ha muerto bajo el manto de la Virgen del Pilar, con la fe firme y sencilla del centurión del Evangelio, con la entrega total y apasionada de su vida al servicio de España, pidiendo perdón y perdonando a todos sus hermanos.

Como cristianos y como españoles, ante el ejemplo de su vida y de su muerte correspondamos con nuestra oración, con nuestra concordia y con nuestra esperanza al mensaje de paz y unidad fraterna que, en los mismos umbrales de su muerte, Francisco Franco ha legado, con un abrazo de despedida a todas las generaciones españolas, a saber: nuestro esfuerzo permanente y esperanzado para alcanzar la justicia social y la cultura para todos los hombres de España». Boletín Eclesiástico Oficial del Arzobispado de Zaragoza, 11, noviembre de 1975, p. 341.

22 AEESS R237 bis. Carta del Nuncio en España al Arzobispo de Zaragoza. Madrid, 24 de julio de 1974.

Hispania Sacra, Legalidad y conflictos, 58 117, enero-junio 2006, 223-260, ISSN: 0018-215-X 
da por todos y cada uno de los implicados. Los clérigos rebeldes le informaban de que ninguno de ellos había sido ni «coaccionado, o condicionado» para haber hecho lo que habían hecho, y no se arrepentían de lo que había sido su actuación posterior. Responsabilizaban a Cantero y sólo a éste de la destitución del Párroco de Fabara, recordándole que no había «oído ni una sola vez al reo antes de emitir sentencia» ${ }^{23}$. Por lo tanto, «el grupo de los $24 »$ exculpaba al Vicario General de Pastoral para los Pueblos de cualquier maniobra para hacer cambiar a Delso de actitud.

Así, estos sacerdotes acusaban a su arzobispo de haber «condenado como convicto y con una pena canónicamente gravísima que le difama de hecho, sin saber realmente y concretamente de qué y por qué» ${ }^{24}$ al Párroco de Fabara, lo que de facto imposibilitaba y hacía «inútil todo intento de defensa y de posterior rehabilitación».

En ese sentido, lo que más reprochaban «el grupo de los 24» era el hecho de que Cantero no hubiera hecho «(...) lo humanamente posible, por todos los medios al alcance de la autoridad judicial, por averiguar con ecuanimidad e imparcialidad la verdad subyacente en el fondo de esas delaciones» ${ }^{25}$. El escrito concluía con una justificación de la actuación de todos ellos, en la medida que el procedimiento llevado a cabo contra Delso se encontraba marcado por numerosos errores y, por tanto, no resultaba de ninguna manera válido:

\footnotetext{
«Esta mi postura es de tal radicalidad, en cuanto afecta a estos fundamentales principios éticos y cristianos, que, en su defensa y exigir su forzoso cumplimiento, no dudo en arrostrar todas las consecuencias humanas y responsabilidades legales, teniendo sereno el ánimo y firme la voluntad, pues no de otro modo actuaron N.S. Jesucristo y sus Apóstoles: "Juzgad vosotros si es justo delante de Dios obedecer a vosotros más que a Dios".

Considere también Vd. con serenidad y ecuanimidad, si mi postura es digna de respeto y si está realmente dentro de la línea del Evangelio, para cuya proclamación he sido constituido ministro y en cuya defensa estoy llamado a ser radical, a imitación de N.S. Jesús y su Primera Comunidad Cristiana.

Pues, si cedo ante lo que creo una injusticia, ¿cómo voy a pedir a los demás respeto al Evangelio con auténtico compromiso personal, si soy yo el primero en regir, por temor humano las consecuencias penosas que impone?
}

${ }^{23}$ AEESS R237 bis. Carta de un grupo de sacerdotes al Arzobispo de Zaragoza. Zaragoza, 28 de julio de 1974. Hay que decir que, al menos en el documento que se ha conservado en el archivo de la embajada de España ante la Santa Sede, se observa la firma de sólo seis personas: Rafael Aranda Rodrigo, Ecónomo de Almonacid de la Cuba y Encargado de Letux; Isidro Jesús Cabello Laborda, Ecónomo de La Ginebrosa y Encargado de Belmonte de Mezquín y de Cañada de Verich; Luis Bel Cortés, Ecónomo de Santa Anastasia y Encargado de El Bayo y de El Sabinar; José Luis Cuartero Lanzán, Ecónomo de Mediana de Aragón y Encargado de Rodén; Jesús Borao, Ecónomo de Valderrobres y Encargado de Beceite; y Francisco Chueca Sancho, Ecónomo de La Portadilla y Encargado de Fórnoles y de Rafales.

${ }^{24}$ Ibidem.

25 Ibidem.

Hispania Sacra, Legalidad y conflictos, 58

117, enero-junio 2006, 223-260, ISSN: 0018-215-X 
Hago a Ud., con mi mayor deseo de sinceridad y humildad, un llamamiento a que, sin dejarse arrastrar por cualquier pasión humana reconsidere su postura ante estos hechos. Y sepa Ud. que, sin ningún átomo de soberbia y con el mayor dolor íntimo, estoy personalmente dispuesto, a dejar el ejercicio pastoral del sacerdocio en los cargos por Ud. encomendados y arrostrar todas las infamias y calumnias que de este hecho se originen a partir del día 4 de Agosto. Si estas realidades no afectan al corazón pastoral de Ud. sirvan al menos para hacer pensar y reflexionar al resto del Pueblo de Dios.

Por el respeto y obediencia que le debo y tengo, por el bien de la Diócesis y por el bien de la Iglesia Universal le ruego y suplico se esfuerce, guiado por el Evangelio y el Espíritu de Cristo, en lograr lo más rápidamente posible, una solución cristiana y pacífica» ${ }^{26}$.

A pesar de la dureza y radicalidad de esta carta, no puede decirse que la relación entre Cantero y estos sacerdotes hubiera sido siempre de abierto enfrentamiento: no, al menos, con todos ellos. Sólo unos meses antes, concretamente el 2 de febrero de 1974, Cantero había defendido a uno de ellos, Jesús Borao, cuando este fue multado por el Gobierno civil tras haber solicitado dinero a sus fieles precisamente para pagar otra multa que poco antes había sido impuesta a ese mismo sacerdote. Cantero decidió entonces escribir al Gobernador Civil de Teruel, José Manuel Hernández Manjón, para pedirle que retirara dicha multa ya que no constituía una infracción de la ley el suplicar una ayuda económica «para fines de caridad fraterna». Hay que tener en cuenta que la decisión de este gobernador estaba teniendo repercusiones en la diócesis aragonesa, ya que el clero más joven se estaba negando a predicar el Evangelio en señal de protesta. Cantero recordaba a Hernández Manjón que, así como había estado de acuerdo con la autoridad civil a la hora de multar la primera vez a Borao, ahora no podía estarlo precisamente porque no se cumplían los requisitos formales para imponer esa segunda multa ${ }^{27}$.

En esta constante tensión hubo un hecho que vino a encrespar aún más los ánimos, y fue la afirmación de que Cantero había amenazado a estos sacerdotes con una posible excomunión si no renunciaban a su actitud rebelde ${ }^{28}$. Esta afirmación fue rebatida de manera absolutamente contundente a través de una nota de la oficina de medios de comunicación social del arzobispado de Zaragoza.

26 Ibidem.

27 Véase al respecto AEESS R237 bis. Carta del Arzobispo de Zaragoza al Gobernador Civil de Teruel. Zaragoza, 2 de febrero de 1974. Cantero escribía al Gobernador Civil de Teruel y no al de Zaragoza porque Borao era Ecónomo de una parroquia (Valderrobres) que, aunque estaba bajo la jurisdicción eclesiástica de la archidiócesis de Zaragoza, se encontraba bajo la tutela civil del gobierno de Teruel.

28 En Pueblo de Dios, la publicación del obispado de Huesca, estos sacerdotes afirmaban que junto en la carta de Cantero de 6 de julio de 1974 iba una «addenda» que consistía en un documento de la Sagrada Congregación del Concilio de 29 de junio de 1950 donde se advertía de posibles casos de excomunión, dando a entender que sobre la cabeza de estos clérigos se cernía una posible «pena capital» (desde el punto de vista católico, recordamos que los excomulgados quedan fuera de la Iglesia). Véase Pueblo de Dios, 15, 21 de julio de 1974, p. 21. 
No sólo no se había amenazado a nadie con esta excomunión, sino que, como recordaba el obispado aragonés, Cantero había dado cargos de gran responsabilidad a personas integrantes del llamado «grupo de los 24» y, además, les había

«(...) apoyado en reiteradas y graves situaciones creadas ante la autoridad civil y el Tribunal del Orden Público por sus actuaciones pastorales en homilías y reuniones pastorales» ${ }^{29}$.

Así, se acusaba al llamado «grupo de los 24» de haber intentado desorientar y manipular a la opinión pública, así como de haber vertido datos «absolutamente desprovistos» de objetividad, actitud que contrastaba con el silencio mantenido por el arzobispado en todo este asunto a fin de no crear un clima de desconcierto y desunión cuando precisamente estaba a punto de celebrarse el Año Santo de la Conversión y de la Reconciliación. Se recordaba, por otra parte, que Cantero había contado en su decisión con el apoyo unánime de los vicarios generales, del Colegio de Arciprestes y del Consejo Presbiteral. El comunicado finalizaba con una nota de la redacción donde se detallaba la última conversación mantenida con Pedro Cantero sobre este turbulento asunto:

\footnotetext{
«Ayer, a última hora de la noche, establecimos contacto telefónico con el señor arzobispo que se halla descansando en su pueblo natal, Carrión de los Condes. A través de sus palabras se adivinaba un ánimo entristecido, pero profundamente sereno. Su seguridad de haber obrado con rectitud, en conciencia, y en defensa de la verdad y de la unión eclesial de su diócesis compensa (nos dijo) la pena que inevitablemente le está produciendo este doloroso asunto.

(...) Al preguntarle si, según la noticia difundida por el periódico madrileño Informaciones, había amenazado a los sacerdotes con la excomunión, nos aseguró que jamás había pronunciado esa palabra ni nunca había pasado ni siquiera por su mente utilizar semejante pena canónica» ${ }^{30}$.
}

\section{UNA DIMISIÓN COLECTIVA ACEPTADA}

El 7 de agosto se anunciaba lo que parecía ya prácticamente inevitable, ante esta ausencia de entendimiento: Pedro Cantero, con el apoyo de los vicarios generales del arzobispado $^{31}$ y con el de los arciprestes bajo cuya tutela se encontraba uno o varios de los miembros del llamado «grupo de los 24», aceptaba la

29 AEESS R237 bis. Nota de la oficina de medios de comunicación social del arzobispado de Zaragoza. Zaragoza, 1 de agosto de 1974.

30 Ibidem.

31 El cabildo metropolitano de Zaragoza le había felicitado poco antes al cumplirse diez años desde la llegada de Cantero a la diócesis aragonesa, asegurando que para todos ellos el prelado palentino era «(...) la mejor garantía de nuevas y mejores realidades en el futuro». AEESS R237 bis. Carta del cabildo metropolitano de Zaragoza al Arzobispo de Zaragoza. Zaragoza, 18 de julio de 1974.

Hispania Sacra, Legalidad y conflictos, 58

117, enero-junio 2006, 223-260, ISSN: 0018-215-X 
dimisión de los 25 sacerdotes $^{32}$ implicados en el asunto. Este hecho se hizo público a través de una nota oficial del arzobispado en la que se recordaban las ideas ya manejadas con anterioridad: que en todo momento se había intentado llevar el asunto con la mayor discreción posible, pero que la actitud del «grupo de los 24» había impedido dicha discreción; que era falso que en todo este proceso sólo se hubiera oído a «autoridades y a los ricos», pues Delso había podido explicar públicamente su postura con el propio Arzobispo de Zaragoza presente y había preferido optar por el silencio; que en ningún momento se había hablado de una posible pena de excomunión, y así se lo había hecho saber Pedro Cantero tanto al Obispo de Huesca, Javier Osés, como al de Tarazona, Francisco Álvarez Martínez ${ }^{33}$; que nunca se había intentado ir contra una «determinada línea pastoral» que se encontraba en relación con el mundo del trabajo; y que, en cualquier caso, a pesar de haber aceptado la dimisión de estos veinticinco sacerdotes, Cantero se encontraba «con los brazos abiertos» para acoger a estos clérigos si alguno decidía rectificar en su conducta ${ }^{34}$.

Como era de esperar, las reacciones se produjeron, aunque no de manera inmediata, ya que todo sucedió en plenas vacaciones del mes de agosto. Y estas reacciones afectaron muy directamente a los compañeros de Cantero: esto es, al resto de los obispos que integraban el episcopado español. Los que primero escribieron fueron los más directamente afectados por lo sucedido, es decir, los prelados de la misma provincia eclesiástica que Cantero: Álvarez Martínez, Tarazona, Osés, Huesca, y Damián Igualen, Barbastro ${ }^{35}$. La carta, escrita personalmente por Iguacen, no da muestras de apoyo hacia Cantero, pero tampoco de estar disconformes con lo sucedido. Se limitaba a proponer un encuentro de todos los obispos de la provincia, propuesta que hacía con gran urgencia pues Iguacen no esperó a que Cantero volviera de sus vacaciones, sino que se la en-

32 Veintiuno de ellos tenían en ese momento cargo parroquial, mientras que había uno que era Consiliario diocesano de la HOAC, otro Profesor de Religión del Instituto Técnico de Enseñanza Media de Ejea de los Caballeros, otro Asesor Religioso del Apostolado de la Carretera y un último que, habiendo sido designado Coadjutor de una parroquia zaragozana desde varios meses antes, todavía no había tomado posesión de su cargo.

33 Francisco Álvarez Martínez, hombre de extraordinaria discreción, disfrutaría de una brillante carrera eclesial que tendría como hitos principales los obispados de Tarazona (1973-76), Calahorra-La Calzada-Logroño (1976-89) y, finalmente, la sede primada, Toledo (1989-2002). Juan Pablo II recompensaría su trayectoria con la elevación al cardenalato en febrero de 2001.

${ }^{34}$ AEESS R237 bis. Nota oficial del arzobispado sobre la dimisión colectiva de veinticinco sacerdotes. Zaragoza, 7 de agosto de 1974.

35 Recordemos que había dos diócesis más en la provincia eclesiástica. Una de ellas era Teruel, que se encontraba en ese momento vacante tras el fallecimiento, en octubre de 1972, de su último inquilino, Juan Ricote Alonso; sería precisamente a Iguacen a quien Roma enviaría a Teruel pero ya en septiembre de 1974, siendo a su vez sustituido en Barbastro por Ambrosio Echebarría. La otra era Jaca, a cuyo frente que se encontraba desde hacia casi un cuarto de siglo el riojano Ángel Hidalgo, pero nada se hablaba de él. 
vió a su Carrión de los Condes natal mientras este disfrutaba de su descanso veraniego. Es más, Iguacen proponía una fecha, el 6 de septiembre, al objeto de que pudieran reunirse todos y hablar de lo que tanto les preocupaba, si bien mostraba total respeto por cualquier otra fecha. Y se despedía de una manera afectuosa dentro de una relativa distancia: «Que pase unos días tranquilos y felices y descanse de tanto trabajo y sufrimiento» ${ }^{36}$.

No obstante, las muestras de adhesión hacia Cantero no tardaron en llegar. La primera de la que tenemos constancia corresponde a la corporación municipal de Fabara, que dijo:

«Como fieles cristianos y feligreses de la Parroquia de Fabara, no sólo aprobamos su actitud inquebrantable demostrada al velar por la integridad y seguridad de la doctrina verdadera de nuestra fe y por la salvación de las almas, sino que nos solidarizamos unánimemente con el Consejo Metropolitano, Colegio Arciprestal y Colegio Presbiteral, en nuestra más afectuosa adhesión a V.E.R.

Aprovechamos la ocasión para testimoniarle nuestra más sincera gratitud, obediencia y amor a nuestra Santa Madre la Iglesia de Dios y a V.E.R.

Lo saludamos en Cristo.

Toda la Corporación Municipal» ${ }^{37}$.

Por esas mismas fechas Cantero recibiría la adhesión total de un miembro del episcopado que se había distinguido por sus posiciones enormemente conservadoras. Se trataba de Ángel Temiño, un burgalés que llevaba ya más de veinte años al frente de la diócesis de Orense (el único destino en toda su carrera) y que ya había tenido importantes conflictos dentro de su diócesis tanto con el clero como con los fieles del llamado sector «contestatario». La carta que Temiño escribió a Cantero merece ser reproducida en su integridad pues constituye una buena muestra del hartazgo de un sector del episcopado, en ese momento minoritario, en relación con los cambios que estaba viviendo la Iglesia desde el Concilio Vaticano II:

«Muy querido y recordado Hermano y amigo:

Leo, con estupor, lo que nos va ofreciendo la prensa sobre ese grupo de sacerdotes de esa diócesis. No sabes lo muy presente que te tengo en estos momentos.

Los que hemos pasado por trances más o menos parecidos sabemos que es fruto de los tiempos. Más que nunca hace falta recordar lo de S. Pablo: "non quae sua sunt", sino lo que es de Cristo. Lo demás no debe importarnos. Hace falta que nosotros mengüemos para que crezca el Reino de Dios.

¡Anímate! Ante el Sagrario podrás encontrar el alivio espiritual fruto del verdadero Espíritu de Dios. Si no tratamos de santificarnos con las cruces que el Señor nos manda me temo que las que nosotros nos busquemos serán ficticias.

36 AEESS R237 bis. Carta del Obispo de Barbastro al Arzobispo de Zaragoza. Barbastro, 29 de agosto de 1974.

37 AEESS R237 bis. Carta de la Corporación Municipal de Fabara al Arzobispo de Zaragoza. Fabara, sin fecha.

Hispania Sacra, Legalidad y conflictos, 58

117, enero-junio 2006, 223-260, ISSN: 0018-215-X 
Repito que te tengo muy presente. Pediré al Señor para que te conceda el ser un buen Cireneo. Ten presente que no hay apostolado verdadero sin el sacrificio que supone la entrega total y el olvido de uno mismo. Lo otro, lo de la contestación, es un fruto de la moda. Olvida.

Un muy fuerte abrazo de tu Hermano y amigo» ${ }^{38}$.

No sabemos la fecha exacta en la que fue escrita esta carta, aunque debió ser, con bastante seguridad, durante el mes de agosto de 1974. En ese mismo mes también escribió a Cantero para mostrarle su apoyo el Obispo de Tenerife, Luis Franco. Su mensaje era lacónico en palabras pero suficientemente expresivo: «Mi venerado y querido Hermano: Sólo dos letras para manifestarle que le he acompañado en espíritu en ese feo y molesto asunto» 39 .

Más amplia fue la carta de Teodoro Cardenal, Obispo de Osma-Soria, quien dejaba claro no sólo su apoyo a Cantero, sino también su total sintonía con la manera de actuar del Arzobispo de Zaragoza:

«Muy respetado y querido D. Pedro:

Apenas llegado de una temporadilla de agua para el riñón que he pasado en el Balneario de Corconte, me apresuro a dirigirle estas líneas de plena adhesión a su actitud pastoral, y de enhorabuena por su perfecta línea, hecha de una gran caridad con una serena firmeza.

Excuso decirle lo que en esta temporada le he recordado y encomendado. Me pareció mejor esperar el final del "affaire" y desde casa escribirle.

En la línea del mejor afecto y respeto y sabiendo que siempre me hallo a su disposición, le saluda, abraza y encomienda,

Teodoro» ${ }^{40}$.

En una línea más moderada de apoyo se movía el prelado de Lérida, Ramón Malla. Este catalán nombrado obispo en los primeros tiempos de Dadaglio como Nuncio en España, estaría al frente de la diócesis ilerdense nada menos que treinta y un años, hasta que Juan Pablo II aceptó su renuncia, ya sobrepasados los setenta y siete, como Obispo de Lérida. Pues bien, Malla escribía a Pedro Cantero para mostrarle su solidaridad por el trance en el que se encontraba el prelado palentino, asegurando haber rogado a Dios para que Cantero fuera capaz de actuar con «(...) la firmeza, que es exigencia de muchos y buenos sacerdotes y fieles y que pide la recta ordenación de la Iglesia» ${ }^{41}$, por un lado, «(...) y a la vez la caridad y delicadeza incluso para quienes no fueran merecedoras de ella ${ }^{42}$. De todas maneras, no era la contundencia lo que presidía las

38 AEESS R237 bis. Carta del Obispo de Orense al Arzobispo de Zaragoza. Orense, sin fecha.

39 AEESS R237 bis. Carta del Obispo de Tenerife al Arzobispo de Zaragoza. La Laguna, 10 de agosto de 1974.

40 AEESS R237 bis. Carta del Obispo de Osma-Soria al Arzobispo de Zaragoza. Burgo de Osma, 13 de agosto de 1974.

41 AEESS R237 bis. Carta del Obispo de Lérida al Arzobispo de Zaragoza. Lérida, agosto de 1974.

42 Ibidem. 
palabras de apoyo de Malla, ya que aseguraba pensar que Cantero se había movido en la línea adecuada «por las notas de prensa» ${ }^{43}$ que le habían hecho llegar.

En cambio, quien sí mostró gran afecto y comprensión por el Arzobispo de Zaragoza fue el Obispo de Orihuela-Alicante, Pablo Barrachina, al igual que Temiño uno de los prelados más conservadores de su generación. La moderación de Malla se convertía, en el caso de Barrachina, en abrumadora contundencia por parte de quien también estaba harto de lo que había visto en los últimos años dentro de la Iglesia española:

\footnotetext{
«Mi querido Hermano y amigo:

Hace semanas que deseo escribirte, con motivo de los sucesos de la parroquia de Fabara; un día de estos pasados leí, descansando en mi pueblo ${ }^{44}$, un artículo tendencioso de "Sábado Gráfico" y no quiero que mis letras se demoren por más tiempo, aunque no las necesites.

Sin duda, como ocurrió en mi diócesis, los «contestatarios» de la tuya se quisieron aprovechar de la terquedad del párroco de Fabara, o quizá éste ya se mostró así porque esperaba la reacción de sus "amigos". Por todo ello, y debido a la experiencia que tengo, gocé cuando te mantuviste firme. Es la única manera de gobernar y de que vayan volviendo las cosas a su cauce, aunque otros opinen de otra forma y sean más considerados en las alturas. Mi felicitación y enhorabuena. A tu disposición.

Un abrazo fraternal,

Pablo, Obispo» ${ }^{45}$.
}

Otras muestras de afecto o, al menos, de comprensión por los malos momentos que estaba viviendo Pedro Cantero, procedieron de Barbastro (Damián Iguacen), Tuy-Vigo (Fray José López Ortiz) e incluso de personas no pertenecientes al episcopado (al menos desde un punto de vista efectivo, es decir, no honorífico), como era el caso de Amadeo Colom Freixa, Prelado de Honor de Su Santidad y Deán de la S.I. Catedral de Lérida. También le mostraría su apoyo la Acción Católica general de la propia localidad de Fabara.

Todo lo sucedido ponía de manifiesto lo aislado que se encontraba a la altura de finales del franquismo el sector más conservador del episcopado español. Ningún obispo perteneciente a una gran diócesis escribió a Cantero: ni Tarancón, Madrid-Alcalá, ni Jubany, Barcelona, ni Bueno Monreal, Sevilla). Tampoco lo habían hecho los prelados conservadores mejor situados, que eran José María García Lahiguera, Valencia y Ángel Suquía, Santiago. En realidad, el

43 Ibidem.

44 Ese pueblo era Jérica (Castellón), donde había venido al mundo el 31 de octubre de 1912. Barrachina compartía con Malla el hecho de haber estado al frente de la misma diócesis un largo período de años (treinta y cinco) y de no haber promocionado a ninguna otra.

45 AEESS R237 bis. Carta del Obispo de Orihuela-Alicante al Arzobispo de Zaragoza. Alicante, sin fecha.

Hispania Sacra, Legalidad y conflictos, 58

117, enero-junio 2006, 223-260, ISSN: 0018-215-X 
problema parecía más propio de Cantero que del sector al que pertenecía, pues no daba la impresión de contar con especial predicamento dentro del conjunto del episcopado, ya que en ese momento había alrededor de setenta obispos en España, entre residenciales y auxiliares, y apenas diez se habían interesado por su situación. Probablemente todo ello haría aún más penosa la situación del prelado palentino, que habría de afrontar nuevos episodios de este turbulento asunto.

\section{NuEVOS INTENTOS DE DIÁLOGO}

En efecto, nada más acabar el verano, pudo vislumbrarse un nuevo intento de entendimiento entre las partes en conflicto. El 15 de septiembre Pedro Cantero se reunió con una comisión delegada del grupo de treinta y cuatro sacerdotes dimitidos, reunión en la que también tomaron parte los vicarios de Cantero y una representación de tres arciprestes.

El grupo de sacerdotes rebeldes presentó sus peticiones, que se resumían en lo siguiente: reposición inmediata de Wirberto Delso, ya fuera como Párroco o Coadjutor de Fabara, como adscrito a Fabara con reconocimiento de misión rural en el mismo, o como Párroco de otro pueblo, en ese caso contando con la consulta a la comunidad cristiana de Fabara, que, como hemos visto, se había volcado de manera muy significativa con su sacerdote; en caso de ser aceptada esta primera exigencia, reposición automática de todos los sacerdotes dimitidos en sus respectivos cargos previos a la presentación de su dimisión, lo que aseguraba la ausencia de represalias al menos inmediatas; y, en caso de ser aceptados los puntos primero y segundo, se presentaría una declaración conjunta de arzobispo y grupo de dimitidos en la que se comunicaría el fin del conflicto, teniendo presente la proximidad del Año Santo de la reconciliación.

Según el documento que los sacerdotes dimitidos presentaron a Cantero al día siguiente de aquella reunión (16 de septiembre), parece que en ella el Arzobispo de Zaragoza admitió el punto primero en su forma, aunque con la reserva de nombramiento indistinto de Párroco o Coadjutor y sin hacer ninguna consulta ni a la comunidad cristiana ni al pueblo de Fabara. También pareció aceptar el punto segundo, admitiendo en bloque para el servicio diocesano a todos los dimitidos, aunque con la salvedad de que cuatro de los sacerdotes del grupo (cuyos nombres no se detallaban) no podrían regresar a sus mismos pueblos por haber recibido Cantero quejas de los pueblos respecto de los mismos. Y también dio la impresión de estar de acuerdo con el punto tercero, concretándose el método de redacción mediante un escrito realizado por los sacerdotes dimitidos que sería revisado con posterioridad por el Arzobispo de Zaragoza. 
Entonces el grupo de clérigos rebeldes decidió puntualizar la contrapropuesta de su arzobispo, señalando que la solución más positiva para Delso era, o reponerle como Párroco o Coadjutor de Fabara, o adscribirle a Fabara con reconocimiento de misión rural en el mismo. Pero, si las circunstancias obligaban a Delso a tener que marcharse de Fabara, entonces los sacerdotes dimitidos tenían algo que decir al respecto:

\begin{abstract}
«Nos parece esencial la consulta a la comunidad de Fabara en el caso de tener que salir D. Wirberto del pueblo, que es la máxima cesión hasta la que podemos llegar. Ofrecer a D. Wirberto un cargo pastoral en un pueblo, sin la consulta a la comunidad de Fabara, no es suficiente hoy para la rehabilitación total de la persona de D. Wirberto, si tenemos en cuenta el tiempo transcurrido desde su destitución y las implicaciones públicas habidas entretanto, en las que su dignidad personal ha sido denigrada. Por ello, mantenemos como necesaria la consulta al pueblo de Fabara» ${ }^{46}$.
\end{abstract}

Es más, en el caso de que Cantero se mantuviera firme en su posición de remover a Delso de su cargo en Fabara, el que podía ser denominado ya «grupo de los 34» exigía a su arzobispo que el nuevo destino fuera una localidad con una población no inferior a la de Fabara (es decir, unos mil quinientos habitantes) y en la que, además, Delso pudiera mantener su categoría de Párroco, lo que evitaba una posible degradación.

La postura de firmeza de estos sacerdotes se hacía todavía más patente cuando llegó el momento de responder a la exigencia de Cantero de que cuatro de ellos no pudieran volver a sus cargos pastorales por no ser queridos en sus respectivos destinos. De ninguna manera podían admitir esto: todos, y no sólo una parte de ellos, debían ser readmitidos en sus puestos anteriores a la dimisión, porque, de no ser así, el problema del Párroco de Fabara se multiplicaría por cuatro. Así, lo único a lo que estaban dispuestos era a que estos cuatro sacerdotes acudieran al arzobispado para ser informados por las razones de este veto.

El comunicado del «grupo de los 34» concluía con la notificación de su conformidad a la forma en que se comunicaría el fin del conflicto, si bien dejando claro que, aunque el arzobispo tendría derecho a redactar el texto final, este no se haría público sin antes contar con el «visto bueno» de los clérigos rebeldes. En definitiva, este sector del clero contestatario, como hemos visto, se mantenía firme en su posición de tratar «de tú a tú» a la máxima autoridad de la diócesis.

¿Y qué pasaba, mientras tanto, con el principal afectado por todo este conflicto, es decir, Wirberto Delso? Pues que el 30 de septiembre tuvo conocimiento, al fin, de la decisión tomada por su arzobispo respecto a su futuro. Se la comunicó el propio prelado:

46 AEESS R237 bis. Carta de un grupo de sacerdotes al Arzobispo de Zaragoza. Zaragoza, 16 de septiembre de 1974. La carta, por cierto, iba firmada por tres personas: Félix Cardiel, el polémico Jesús Gil García y Carmelo Martínez.

Hispania Sacra, Legalidad y conflictos, 58

117, enero-junio 2006, 223-260, ISSN: 0018-215-X 
«Muy estimado en Cristo:

En cumplimiento de mis reiteradas ofertas a Vd. de encomendarle un ministerio pastoral en nuestra Diócesis; y después de las consultas e informes recibidos de nuestros hermanos en el Sacerdocio que prestan sus servicios en Alcañiz me es grato ofrecerle a Vd. el cargo de Coadjutor de la Parroquia de Alcañiz.

Espero que, con la buena voluntad de todos, y dentro del espíritu de conversión y reconciliación del Año Santo, podamos dar testimonio evangélico al pueblo de Dios, a cuyo servicio estamos todos comprometidos.

Le agradecería que me comunique cuanto antes la aceptación de este ofrecimiento.

En comunión de oraciones le saluda en el Señor, su afmo.

Pedro, Arzobispo de Zaragoza» ${ }^{47}$.

Pero la respuesta de Delso a este ofrecimiento fue, como ciertamente no podía ser de otra manera, un «no» en toda regla. Por tres razones fundamentales, aunque él no las diera. La primera, que Delso se veía obligado a marcharse de Fabara. La segunda, que, aunque seguiría en el territorio de la diócesis de Zaragoza, se marchaba de la provincia civil, por ser Alcañiz una población perteneciente a Teruel y no a Zaragoza. La tercera, que, aunque Alcañiz era y es una población ostensiblemente más importante que Fabara, en ella Delso sería rebajado de grado, ya que pasaría de Párroco a simple Coadjutor. Estas razones, en todo caso, nunca llegaron a ser directamente expuestas: a Delso le bastó con una simple negativa sin dar más explicaciones, en la idea de que Cantero debía saber perfectamente por qué se negaba a aceptarlo. El 7 de octubre escribió al Arzobispo de Zaragoza:

«Muy estimado en Cristo:

Enterado por su carta del 30 de septiembre de su ofrecimiento del cargo de Coadjutor de la Parroquia de Alcañiz, siento tener que comunicarle que no me es posible aceptar dicho nombramiento.

$\mathrm{Ni}$ el grupo ni yo creemos que este nombramiento sea la solución al problema.

Me reafirmo en lo que el grupo le dijo en carta dirigida a Vd. el 16 de septiembre.

Le saluda en el Señor.

Wirberto Delso» ${ }^{48}$.

\section{UN INFORME POLÉMICO}

Desconocemos si la respuesta de Delso a la propuesta de Cantero era precisamente la esperada por el arzobispo, pero lo cierto es que aquí se acabó el diálogo entre ambas partes. Por si no tenía suficientes problemas en el horizonte,

47 AEESS R237 bis. Carta del Arzobispo de Zaragoza a Wilberto Delso. Zaragoza, 30 de septiembre de 1974

48 AEESS R237 bis. Carta de Wirberto Delso al Arzobispo de Zaragoza. Zaragoza, 7 de octubre de 1974. 
Cantero se encontró con la obligación de tener que informar a la Santa Sede de todo lo que estaba sucediendo en su diócesis, pues Wirberto Delso se había adelantado a su arzobispo y había denunciado el conflicto existente a la Sagrada Congregación del Clero, en un documento que había contado con el apoyo de algunos sacerdotes. Así, el resultado fue un texto de Cantero, porque al escrito por Delso no hemos podido tener acceso, extraordinariamente extenso (28 páginas) que ponía de manifiesto la gran tensión que se respiraba dentro de la diócesis y el hastío que provocaba a un prelado autoritario como Cantero el cambio vivido por la Iglesia en el Posconcilio. Todo un documento escrito para comprender la fractura que vivieron los sacerdotes españoles como consecuencia de un cambio no asimilado en muchos casos.

En ese sentido, Cantero podía encontrar un buen punto de apoyo en la Sagrada Congregación del Clero, ya que al frente de ella se encontraba John Joseph Wright, un conservador cardenal norteamericano a quien Tarancón acusaría en sus memorias de haber colaborado en una maniobra para desestabilizarle por lo sucedido en la Asamblea conjunta de obispos y sacerdotes, celebrada en septiembre de 1971, esperando que sirviera para evitar su elección como Presidente de la Conferencia Episcopal, elección que a la postre acabó produciéndose por amplia mayoría ${ }^{49}$.

Aunque Wright había sido de alguna manera desautorizado por Pablo VI, se había mantenido como Prefecto de esta Congregación hasta ese momento y lo haría hasta su muerte, en agosto de 1979. El problema para Cantero radicaba en que, si bien el Prefecto podía estar de su lado, el Secretario de dicha Congregación, no, pues se trataba del aperturista Maximino Romero de Lema, un antiguo Obispo auxiliar de Madrid-Alcalá que había tenido que dejar la diócesis de la capital por sus continuas desavenencias con el titular de esta, el conservador Casimiro Morcillo. Ello explicaría que Cantero acabara personándose en Roma, ante la posibilidad de que las informaciones sobre lo que él pensaba que estaba sucediendo en su obispado pudieran llegar distorsionadas a Wright.

Otra razón positiva que Cantero podía encontrar para informar directamente a Roma era tener la oportunidad de «pasar por encima» de alguien con quien tenía nula sintonía: el Nuncio Dadaglio. Ya hemos podido ver el cruce de cartas en el que el diplomático vaticano se desentendía de las peticiones de Cantero sobre el caso Fabara. Pero, por si no había todavía suficientes pruebas de esta asintonía, encontramos el documento, si no definitivo, sí muy reafirmante de esta realidad. Se trata de una carta del Embajador de España ante la Santa Sede, Gabriel Fernández de Valderrama, al Ministro de Asuntos Exteriores Pedro Cortina. En ella el diplomático informaba a su superior de que el Arzobispo de Zaragoza se encontraba

49 Este asunto fue tratado en mi libro La Iglesia que se enfrentó a Franco, op. cit., pp. 109-113.

Hispania Sacra, Legalidad y conflictos, 58

117, enero-junio 2006, 223-260, ISSN: 0018-215-X 
«(...) en una situación muy difícil con el Nuncio debido a sus constantes intentos de nombrarle Obispos auxiliares en personas que él no desea y la correspondiente negativa del Nuncio, en cambio, a nombrarle los Obispos Auxiliares que él quiere y tanto ha necesitado en sus últimas crisis de salud y continúan necesitando por su estado avanzado de edad» ${ }^{50}$.

Todo ello llevó, como hemos dicho, a que Cantero preparara un profuso informe sobre lo que había sucedido dentro de su diócesis en los últimos meses en relación con el llamado caso Fabara.

\section{Prolegómenos de una realidad diocesana}

Cantero comenzaba su exposición señalando que sabía de la existencia de un «documento-informe» de más de cincuenta folios que estaba circulando por la diócesis y en el que, además de elogiarse la figura de Wirberto Delso, se criticaba no sólo su actuación en todo este asunto, sino también su gestión como Arzobispo de la diócesis desde que llegara a esta en mayo de 1964. También sabía de la existencia de otro folleto, en este caso exclusivamente gráfico, en el que se buscaba desprestigiar y ridiculizar tanto al Arzobispo como a algunos de sus más cercanos colaboradores.

En ese sentido, el prelado palentino no había querido tener en cuenta ninguno de esos dos documentos, por dos razones. La primera era que no podía hacerse caso a unos documentos cuyos autores, que según el prelado habían contado con la «colaboración eficaz» tanto de un sacerdote secularizado como del Partido Comunista de España, en ese momento todavía en la clandestinidad ${ }^{51}$, buscaban «la publicidad escandalosa y corrosiva» no sólo contra el propio Cantero, sino también contra el magisterio y la obligación de la obediencia a los obispos y pastores que formaban la Iglesia. La segunda razón por la que no hacía caso era la siguiente:

«(...) porque la simple lectura de su contenido (exclusivamente negativo) compuesto de anécdotas sobre el ordinario quehacer pastoral a las que se da una versión parcial y falta de objetividad y, por otra parte, se silencian las realizaciones diocesanas para la aplicación de las enseñanzas y normas del Concilio Vaticano II, da la impresión de puerilidad y falta de consistencia objetiva» ${ }^{52}$.

50 AEESS R237 bis. Carta n. 11 del Embajador español cerca de la Santa Sede al Ministro de Asuntos Exteriores. Roma, 12 de febrero de 1975.

51 Cantero también acusaría de estar detrás de todo este asunto al movimiento Cristianos por el socialismo.

52 AEESS R237 bis. Informe sobre la Instancia presentada a la Sagrada Congregación para el Clero por el Rvdo. Sacerdote D. Wirberto Delso Díez, y suscrita por algunos otros sacerdotes de la Archidiócesis de Zaragoza. Zaragoza, 21 de enero de 1975. 
Desde esa perspectiva, el Arzobispo de Zaragoza no ocultaba su enfado por habérsele obligado a escribir este informe:

\begin{abstract}
«De todos modos, si la SAGRADA CONGREGACIÓN PARA EL CLERO desea que yo conteste al contenido de ambos documentos, cuya redacción, composición y difusión importan cientos de miles de pesetas, lo haré punto por punto y acusación por acusación. Lo triste, lo que con este hacer y deshacer entuertos a problemas creados artificialmente por la actitud de unas minorías «contestatarias», es que los Pastores perdemos el tiempo que deberíamos dedicar totalmente a la edificación del Pueblo de Dios» ${ }^{53}$.
\end{abstract}

Así, Cantero retrocedía hasta mayo de 1974, fecha en la que, como es bien sabido, decidió realizar una visita por los parroquias correspondientes al arciprestazgo de Caspe, al que pertenecía la parroquia de Fabara. El 27 de ese mes había llegado a Fabara, acompañado del Vicario de Pastoral para los Pueblos y del Arcipreste de Caspe, y, tras conocer la situación religiosa de este pueblo por boca de sacerdotes y seglares que la conocían, y una vez que había obtenido el apoyo unánime de los tres vicarios generales de la diócesis, había decidido cesar a Delso como Regente de Fabara (14 de junio), indicándole la conveniencia de dedicar a partir de entonces un tiempo a la oración, al estudio y a la reflexión de la Teología Pastoral.

Gracias a este informe conocemos las razones concretas que habían llevado al cese de Delso, y que hasta el momento, como hemos visto, no habían sido reveladas. Merece la pena transcribirlo literalmente porque pone de manifiesto que el origen del conflicto se remontaba a bastante tiempo atrás:

«a) De forma permanente, durante varios años, ha mantenido una actitud de desprecio y de difamación no sólo hacia mi persona, sino, lo que es peor, hacia la autoridad de la Iglesia en general, y de cualquier estructura de la Iglesia diocesana;

b) Ha enseñado que el órgano auténtico del Magisterio es "la base", el pueblo, en su acepción meramente sociológica y cuantitativa, contraponiéndolo al Papa y a los Obispos;

c) Con verdadera repercusión en los grupos de juventud sobre los que ha actuado, ha enseñado la liberación sexual. He leído una carta confidencial de una joven de FABARA, que refleja una situación moral verdaderamente lamentable;

d) Ha estimulado la rebeldía de los adolescentes para con sus padres en materias en las que la Iglesia siempre ha enseñado fidelidad y obediencia;

e) Ha desvalorizado el precepto dominical de la Santa Misa, y su cumplimiento. Algunos de sus catequistas han manifestado en público no asistir a Misa en los días de precepto;

f) Asimismo alguno de sus catequistas enseña que no puede haber Eucaristía en donde no existe pueblo, hasta el extremo de que carece de sentido una Visita al Santísimo, porque Dios está en todas partes. Con esta mentalidad se explica la grave falta de respeto de D. Wirberto a las normas litúrgicas, v. gr.: ante un grupo de chicas, que se baña-

53 Ibidem.

Hispania Sacra, Legalidad y conflictos, 58

117, enero-junio 2006, 223-260, ISSN: 0018-215-X 
ban en el río en "bikini”, pidió pan corriente y celebró la Misa sin más atuendo que el mencionado;

g) Ha promovido, con prioridad pastoral, la lucha violenta de clases... Y esto en un pueblo en el que aún perduran rescoldos de las heridas de la guerra civil española, y en el que no existen diferencias notables de clases por estar la propiedad bastante bien repartida, ni existir paro obrero;

h) Ha usado un léxico no sólo en sus conversaciones, sino también en sus actividades pastorales, incluso en la homilía, no sólo inadecuado, sino "grosero e indecente" con la consiguiente extrañeza y sorpresa de quienes lo escuchaban» ${ }^{54}$.

El gran problema para Delso había sido, en ese sentido, que tenía «el enemigo en casa». En efecto, entre las personas que habían denunciado la actuación de este sacerdote en Fabara se encontraba... su propio Coadjutor. También el Párroco que había precedido a Delso, así como el Arcipreste de Caspe, habían informado muy negativamente sobre este sacerdote. Además, habían denunciado al Párroco de Fabara los miembros de la Acción Católica general de esta localidad, quienes habían comentado «medio llorando», expresión literal de Cantero, a los dirigentes de la $\mathrm{AC}$ de hombres de Zaragoza que Delso estaba removiendo las heridas de la guerra y que ellos no mandaban a sus hijos a la catequesis por las enseñanzas que este polémico sacerdote estaba dando en relación con la autoridad y obediencia a sus padres y a las relaciones prematrimoniales. Cantero no podía ser, en ese sentido, más duro con la actuación de este sacerdote, el cual, a su juicio, había dejado a la feligresía de Fabara «en una situación deplorable», demostrando, a juicio del arzobispo, que Delso no se encontraba en ese momento «en condiciones de presidir otra comunidad parroquial» ${ }^{55}$.

A partir de aquí, la escalada de tensión había ido en aumento. A Cantero le había molestado profundamente que Delso, en lugar de haberle llamado para mostrarle su disconformidad si es que pensaba que así debía hacer, lo que había optado era por convocar a un grupo de sacerdote para pedirles su apoyo (20 de junio), lo que el prelado palentino debió ver como una apelación a la insurgencia. Además, la carta que el sacerdote le había hecho llegar le parecía que contaba con un apoyo sencillamente ridículo, pues la firmaban sólo 118 personas de una población que contaba con más de 1500 habitantes. Por cierto, que con motivo de estas cifras vertía una nueva acusación caracterizada por un notable tono de dureza:

«Téngase en cuenta que la parroquia tiene 1666 feligreses, de los que el 10\%, especialmente los jóvenes, son adictos de D. Wirberto. El 90\%, según testimonio de los mismos amigos de D. Wirberto, está en contra de él» ${ }^{56}$.

54 Ibidem.

55 Ibidem.

56 Ibidem. 
Las respuestas que se sucedieron, marcadas por una nueva carta de Cantero a Delso y una contestación no de este sino a cargo de un grupo integrado ya por 24 sacerdotes, provocaron, como ya hemos dicho con anterioridad, el redimensionamiento del conflicto, en el sentido de que algo personal entre un prelado y uno de sus sacerdotes pasó a ser un conflicto dentro del conjunto de la diócesis, lo que el propio Cantero, siempre desde su óptica particular de lo sucedido, explicaba así:

«Lo que hasta ese momento era asunto cuyos límites se circunscribían a un acto ordinario del gobierno como es el traslado de un REGENTE, adoptado con ocasión de la Santa Visita Pastoral, sin más ámbito que el comportamiento personal de un sacerdote que por su actitud personal se hace incompatible con su feligresía, es manipulado y explotado por un grupo "contestatario", atribuyéndole dimensiones que excedían y desnaturalizaban su sentido y finalidad pastoral» ${ }^{57}$.

En otras palabras, estos sacerdotes, según el Arzobispo de Zaragoza, no se habían «levantado en armas» contra él por solidaridad con Delso, sino por un deseo de rebelarse contra un prelado cuya manera de gobernar la diócesis desagradaba a este sector del clero.

Y... ¿por qué Cantero había decidido responder de manera individual a los sacerdotes y no al grupo en sí, teniendo en cuenta que se le estaba amenazando con una dimisión en bloque? La explicación dada por el prelado trasciende lo meramente eclesial para convertirse en un conflicto ideológico en toda regla:

\footnotetext{
«Para comprender el espíritu y los hilos que han movido los protagonistas de las implicaciones del CASO FABARA, conviene observar a) que, siguiendo la táctica típicamente marxista, forman un grupo cuyos componentes se comprometen a no actuar individualmente, sino a través y en la forma que adopte el GRUPO reunido en Asamblea; b) el Grupo está manipulado "por unos pocos", que saben a dónde van, que dan las consignas, y que financian los gastos de propaganda, viajes, etc.; c) que, si alguno o algunos de sus componentes actúan o toman decisiones o se apartan del Grupo (como ha sucedido en el CASO FABARA), les insultan y amenazan despiadadamente. "La presión del Grupo es tremenda", confesaba uno de los sacerdotes que, gracias a no haber abandonado su oración y su acusada y recia personalidad, logró marcharse del CÍRCULO de acción del GRUPO» 58 .
}

Así, el Arzobispo de Zaragoza se había visto obligado a convocar las principales jerarquías de la diócesis tras él (los arciprestes) y estos les habían respondido con un apoyo masivo, casi unánime. Mientras, el prelado palentino recordaba que el 28 de julio el grupo de sacerdotes rebeldes se habían dirigido a él a través de «(...) una carta con aires de alegato jurídico, escrito probable-
57 Ibidem.
58 Ibidem.

Hispania Sacra, Legalidad y conflictos, 58

117, enero-junio 2006, 223-260, ISSN: 0018-215-X 
mente por un Abogado» ${ }^{59}$, en la que ratificaban su dimisión. Hay que decir, en ese sentido, que el relato que Cantero hace a la Sagrada Congregación del Clero responde con bastante fidelidad a lo que realmente sucedió, al menos en cuanto a los hechos se refiere: otra cosa bien distinta era la interpretación de los mismos.

\section{Las razones de un cese}

A partir de aquí, Cantero se centraba en la figura concreta de Delso y las razones concretas que habían llevado a su cese. Pero, en este caso en concreto, más que hablar de razones, lo que hacía era recoger testimonios que, de ser ciertos (cosa difícilmente comprobable), nos hablan de un sacerdote bastante más allá de lo meramente «contestatario». Esto relató el Arzobispo de Zaragoza a las autoridades vaticanas:

«Lo cierto es que existió todo el diálogo que era posible, porque la actitud habitual y pública de D. Wirberto ha sido el explícito desprecio de la Autoridad de la Iglesia, la cual debería ser para él, una corriente socio-liberadora caracterizada por la lucha abierta de clases. Así se explican expresiones suyas como éstas:

a) "Hay que hacer ceniza la historia de los 20 siglos de la Iglesia";

b) el término usual referido a sus Superiores ha sido el de "cabrones";

c) en una reunión comarcal de la JARC (en Hijar), dijo al Vicario General: "te aceptamos en la reunión como amigo, no como Vicario";

d) al manifestar el Vicario General la conveniencia de que se nombrase un Consiliario Diocesano de la JARC, dijo: "Si necesitamos Consiliario, nos lo nombraremos nosotros; y si nos nombran otro no lo aceptaremos". De la misma forma se ha manifestado en la Curia algún catequista de FABARA;

e) en otra ocasión al hablarle de los Vicarios Generales de las quejas recibidas por su labor pastoral en FABARA, replicó: “que queréis decir, ¿qué me vais a quitar de Fabara? Si es así os bato las muelas.

f) finalmente llamado a la Curia por el Vicario General de Pueblos, en nombre del Sr. Arzobispo, su saludo de entrada fue: "me vais a quitar"; "hasta ahí podíamos llegar". Después de una larga conversación en la que se le advertía sobre su doctrina y catequesis, se burló abiertamente del Vicario y le dijo que los asuntos tenían que resolverse con diálogo. Interrogado sobre quién debía decidir después del diálogo, manifestó: "Si el Obispo resuelve en contra del súbdito pisoteará los derechos de la persona humana". Al advertirle el Vicario General de la Ciudad su desconsideración para con el Vicario General de Pueblos e indicarle que todo diálogo habría de instaurarse en el sufrimiento, replicó: "para mí ese Evangelio no existe".

g) en la Visita Pastoral, él mismo reconoció que había pasado un trance amargo ante la tensión violenta provocada por las acusaciones públicas. Yo procuré excederme en amabilidad para con él. Cuando el Vicario General de los Pueblos le comentó: "ya has

59 Ibidem. 
visto el resultado; no te aceptan", él contestó: "yo me he trazado una línea y no me muevo de ella. Quien quiera pasar que pase, y quien no, que lo deje". Los días sucesivos a la Visita Pastoral, él esperaba alguna seria amonestación. Al tardar en llegar, por la prolongada reflexión que se hizo en la Curia, ya decía: "yo sigo en FABARA. Nada me han dicho", queriendo significar que todo su modo de decir y hacer, su pastoral, había quedado confirmada» ${ }^{60}$.

En ese sentido, Cantero aseguraba a la Sagrada Congregación del Clero que él nunca se había negado a dialogar con el grupo de sacerdotes rebeldes. Si ese diálogo no había sido posible, era porque estos se habían empeñado en que recibiera a todos juntos, a lo que él se había negado de manera sistemática. Y se había negado porque, según el Arzobispo de Zaragoza,

\begin{abstract}
«(...) la experiencia me ha enseñado que esas reuniones tienen poco de diálogo y mucho de presión, de chantaje, y, a veces, hasta de faltas de educación, de insulto personal; pero les he rogado insistentemente, de palabra y por escrito, que hablasen individual y personalmente conmigo, recomendación que ellos han rechazado abiertamente, mientras difundían la idea de que jamás se les había querido escuchar» ${ }^{61}$.
\end{abstract}

No obstante, a pesar de esta falta de acuerdo entre ambas partes sobre cómo reunirse para discutir los puntos centrales del conflicto, sí había contactos de manera indirecta, como la reunión del Vicario General para los Pueblos con este grupo en el Centro Pignatelli (20 de junio), e incluso el propio arzobispo había llegado a recibir a una parte del grupo con el propio Delso presente $^{62}$.

A partir de aquí, el prelado palentino analizaba de manera minuciosa quiénes habían sido las personas dentro del clero que habían apoyado a Delso. La mayor parte de ellos se habían agrupado, según Cantero, en torno a un colectivo denominado «Grupo Solidario» (que, «(...) desde el principio, puso en práctica las tácticas más afines a la ideología marxista que al Evangelio» ${ }^{63}$, recordaba el arzobispo), formado por 25 sacerdotes, todos ellos pertenecientes al clero secular con la excepción de un jesuita. A estos 25 se habían añadido ocho sacerdotes más, 5 seculares y 3 regulares, que no ostentaban ningún cargo pastoral en la diócesis. Es más, 3 de estos 8 no poseían siquiera la licencia para el ministerio y un cuarto había sido

«(...) despedido de la cátedra de un Centro Diocesano por su enseñanzas opuestas al Magisterio de la Iglesia, y a quién la Diócesis pagó setenta mil pesetas, en concepto de in-

60 Ibidem.

61 Ibidem.

62 «PUEDE DECIRSE, SUPUESTO LO QUE ANTECEDE, QUE LA FORMA DEL CESE FUE INJUSTA POR REPENTIZADA Y FALTA DE DIÁLOGO?», preguntaba Cantero al final de la primera parte de su informe. Véase al respecto Ibidem.

63 Ibidem.

Hispania Sacra, Legalidad y conflictos, 58

117, enero-junio 2006, 223-260, ISSN: 0018-215-X 
demnización, por decisión del Tribunal Laboral, al que había recurrido sin conocimiento del Arzobispado ni del Padre Provincial de su Congregación» ${ }^{64}$.

Desde esa perspectiva, a pesar de la trascendencia que el caso Fabara había tenido en Aragón, el prelado palentino quería recordar que todos estos sacerdotes no suponían siquiera el $5 \%$ del total de su clero, ya que este rondaba los casi mil sacerdotes (509 diocesanos y 354 regulares) y, por tanto, los 35 que tantos problemas le estaban creando tan sólo constituían el $3.85 \%$ del total.

Dentro del llamado grupo de la contestación, Cantero consideraba necesario realizar una subdivisión. Existía, por un lado, un grupo minoritario sumamente radicalizado que llevaba a su pastoral como elemento dominante lo que se conocía en aquellos tiempos como «temporalismo», «la lucha de clases de la dialéctica marxista», a juicio de Cantero. Este grupo había tomado parte en acciones «contestatarias» que en ocasiones tenían tintes eclesiales y, en otras, sencillamente, políticos: es más, según Cantero, algunos de ellos se habían declarado públicamente marxistas y otros habían mantenido contactos con los ilegalizados Partido Comunista de España y el sindicato Comisiones Obreras, lo que les había llevado a participar en algunos de los disturbios laborales que habían tenido lugar en Zaragoza en los últimos tiempos, con toma de calles y encierros en las iglesias.

En convivencia con este grupo minoritario se encontraba el otro subgrupo, de carácter mayoritario, que era tratado con bastante más afecto por Cantero, para quien,

«(...) aunque con una mentalidad social y eclesiológica avanzada, está constituido por buenos sacerdotes, de recta intención, muy jóvenes, y que, sumamente influenciados por los primeros, han sido inducidos a pensar que el cese dado a D.WIRBERTO equivaldría a un "golpe de fuerza" contra la tarea pastoral que ellos representan» ${ }^{65}$.

Así, y siempre según la visión del Arzobispo de Zaragoza, era el primer subgrupo («grupo cerebro») el que había elaborado la estrategia contra su persona, la cual consistía en actuar siempre como grupo, no permitiendo que nadie pudiera desviarse de la línea marcada por ellos: Cantero aseguraba, en ese sentido, que los que se habían atrevido a discrepar habían sido «(...) despiadadamente increpados e insultados por el Grupo» ${ }^{66}$. Al mismo tiempo, habían presentado el caso del cese de Delso como símbolo de la persecución por parte del Arzobispo contra la llamada «Iglesia progresista». Ello había permitido dar a este asunto trascendencia nacional y lograr la solidaridad de algunos movimientos

64 Ibidem.

65 Ibidem.

66 Ibidem. 
nacionales de apostolado social, a pesar de que, según Cantero, no contaban con el apoyo ni de la Comisión Episcopal del Apostolado Seglar ni del Consiliario Nacional de la Acción Católica española.

\section{Cantero y el «Grupo Solidario»}

Lo que más indignaba a Cantero era el hecho de que hubieran tenido muchos gestos hacia este sector del clero él mismo y su equipo de colaboradores, y que este le hubiera «premiado» de esa manera su generoso comportamiento. Y ponía ejemplos de ello.

El primero era que los Vicarios de Pastoral habían mantenido muchas más reuniones con el grupo de sacerdotes obreros que cualquier otro grupo o movimiento de apostolado. En esas reuniones estos vicarios habían hecho todo lo posible por conocer los planes, así como por orientar, potenciar y unir a estos clérigos, lo que resultaba especialmente meritorio si se tenía en cuenta que los sacerdotes obreros, según el prelado palentino, solían mostrarse «muy divididos entre sí». El segundo ejemplo de esta actitud de «mano tendida» había que visualizarla en su intento de formar un grupo social en el campo del pensamiento, que de alguna manera viniera a suceder al que había existido en Zaragoza unas décadas antes. Si esto no había sido posible no fue por falta de voluntad del arzobispado, sino porque no se había encontrado a las personas adecuadas dentro de los seglares y porque los sacerdotes presentaban excesivas divergencias en sus concepciones «eclesiológicas y teológicas».

Tercer ejemplo de su actitud de diálogo. Tiempo atrás había ofrecido a Gregorio Forniés, miembro del grupo de sacerdotes rebeldes y en ese momento Consiliario de la HOAC, el cargo de Vicario Episcopal del Mundo del Trabajo. Pero Forniés había declinado esa oferta siguiendo «la recomendación de unos obreros», que le habían dicho que era más inteligente dedicar unas horas al trabajo manual que aceptar esta responsabilidad diocesana, en la que, a juicio de Cantero, «podía haber desplegado plenamente su línea de pastoral». Esta afirmación del Arzobispo de Zaragoza resulta, a nuestro juicio, bastante creíble, porque era habitual que los sacerdotes del mundo obrero prefirieran realizar su labor pastoral trabajando como un obrero más que estando destinados en una parroquia que se situara en zona obrera pero sin salirse de su categoría estrictamente sacerdotal ${ }^{67}$.

${ }^{67}$ Uno de los casos más paradigmáticos de ello lo constituye el alcarreño Mariano Gamo, quien, siendo sacerdote de la diócesis de Madrid-Alcalá, quiso convertirse en un obrero más sin secularizarse, lo que le acarreó serios conflictos con el entonces arzobispo, Casimiro Morcillo. Así lo señalé en mi contribución «El nombramiento de Vicente Enrique y Tarancón para la archidiócesis de Madrid-Alcalá», en Iglesia y Religiosidad en España. Historia y Archivos. Actas de las V Jornadas de Castilla-La

Hispania Sacra, Legalidad y conflictos, 58

117, enero-junio 2006, 223-260, ISSN: 0018-215-X 
Como cuarto ejemplo de su línea de colaboración con el sector más aperturista del clero Cantero recordaba los importantes medios que había dedicado a la fundación diocesana Fuenclara, entre ellos un edificio valorado en la astronómica cifra, para la época y tratándose de la diócesis de Zaragoza, de unos cien millones de pesetas, para que esta fuera dedicada a la pastoral obrera. Qué había sucedido con ese proyecto lo explicaba el propio Cantero de la manera más cruda posible:

\begin{abstract}
«Cuando se iniciaron las gestiones para ofrecerles la Fundación con el fin de que les sirviera de base para un moderno planteamiento de la pastoral obrera, fue tal la apatía y el desprecio manifestados que hubo de desistir de ello. Alguno comentó que la única pastoral válida era el compromiso por la liberación del pueblo haciéndose obreros con ellos y como ellos» ${ }^{68}$.
\end{abstract}

Más ejemplos de hasta qué punto había sido, según Cantero, flexible en su actitud. Parece ser que los encargados de la Juventud Obrera Cristiana (JOC) diocesana, «alegre e irresponsablemente» en palabras del prelado palentino, habían querido abandonar la propiedad de una residencia obrera en la que vivían unos setenta aprendices procedentes de pueblos «en un régimen admirable de autogobierno» y bajo «unas condiciones económicas inmejorables». Cantero aseguraba que los responsables de la JOC le habían dicho que el único planteamiento válido para todos ellos era «la lucha de clases». Si esta residencia había seguido funcionando, era porque el propio arzobispado, y no la JOC diocesana, se había encargado de gestionarla.

Peor aún había sido el asunto de tres sacerdotes pertenecientes al llamado «Grupo Solidario». Tan sólo ocho días después de ser ordenados, se habían negado a aceptar lo que solía ser norma en la diócesis, que era el de aceptar un destino en el mundo rural; en lugar de marchar a este, se habían puesto a trabajar en una fábrica. «Nunca había ocurrido nada semejante en la Diócesis, y, por tanto, el escándalo en el presbiterio diocesano fue grave» ${ }^{69}$, recordaba Cantero. La solución no pudo ser más traumática: los sacerdotes rompieron toda comunicación con su arzobispo y este decidió retirarles sus licencias ministeriales. A pesar de ello, había encargado a sus vicarios generales que mantuvieran el diálogo con estos sacerdotes, prometiéndoles a través de ellos que, si normalizaban sus relaciones con la diócesis y con el presbiterio, podían no sólo seguir como sacerdotes, sino mantener su carácter obrero. «Su respuesta ha sido fir-

Mancha sobre Investigación en Archivos, Guadalajara, Anabad Castilla-La Mancha, 2002, pp. 411432.

68 AEESS R237 bis. Informe sobre la Instancia presentada a la Sagrada Congregación para el Clero por el Rvdo. Sacerdote D. Wirberto Delso Díez, ya citado.

${ }^{69}$ Ibidem. 
mar la declaración del Grupo Solidario, a pesar de que no tienen cargo pastoral alguno» ${ }^{70}$.

Dentro de esa línea de flexibilidad con los llamados sacerdotes obreros había que señalar muy especialmente el caso de cinco clérigos, a los que se había permitido seguir percibiendo la nómina de la diócesis a pesar de que estaban cobrando al mismo tiempo su sueldo como obreros ${ }^{71}$.

En ese sentido, lo que Cantero no pensaba admitir de ninguna manera era que se le pudiera calificar de «no social», es decir, de no estar interesado en los problemas que afectaban a la sociedad aragonesa. Prueba de ello era, por ejemplo, las gestiones que había hecho, previo acuerdo con la Presidenta de la JOC femenina, ante el ministerio de Trabajo para lograr que muchas asistentas pudieran ingresar en el sistema de la Seguridad Social y, en definitiva, a regularizar sus condiciones de trabajo. Prueba de ello era también la promoción que se había realizado del sector gitano de la ciudad, con un plan de construcción de seiscientas viviendas propuesto por el propio arzobispado y con aportaciones de dinero realizadas por la diócesis. Y prueba de ello era la defensa que había realizado de la publicación semanal Eucaristía, de conocido signo progresista, ante el ministerio de Información y Turismo, que quería cerrarla: «a pesar de no estar de acuerdo personalmente con la orientación y el contenido de dicha publicación», había sido una intervención suya personal y de su Vicaría Pastoral la que había impedido dicho cierre ${ }^{72}$. De hecho, aseguraba Cantero, los responsables de esta publicación le habían hecho llegar una «amable dedicatoria de reconocimiento» en diciembre de 1973 para mostrarle su agradecimiento por la defensa que había hecho de la publicación ${ }^{73}$. Aquí se veía al Cantero más tajante:

«Siempre he defendido a los miembros del GRUPO SOLIDARIO y a otros Religiosos cuando las Autoridades civiles han intentado procesarles o los han sancionado con multas por sus intervenciones públicas» ${ }^{74}$.

Entre esas defensas debían destacarse las que había llevado a cabo cuando, por ejemplo, el Capitán General de Zaragoza, que venía enviado por el ministro de la Gobernación en una de las dos ocasiones que le visitó, le solicitó licencia para procesar al sacerdote Jesús Borao. Cantero había tenido que ampararse en el Fuero del Concordato de 1953 para impedirlo, a pesar de que, según él mismo, existían serios indicios de actividad delictiva. Otros sacerdotes beneficiados por su actitud «paternalista» habían sido Porfirio Pascual, que había sido

\footnotetext{
70 Ibidem.

71 Se trataba de Jesús Molinero, Laureano Molina, Ángel Nogueras, Álvaro Lacaste y Vicente Rins, éste último ya secularizado en el momento de escribir Pedro Cantero su informe.

72 Ibidem.

73 Los responsables eran José Bada, ya secularizado, Luis Betés y Mariano García Cerrada.

74 Ibidem.
}

Hispania Sacra, Legalidad y conflictos, 58

117, enero-junio 2006, 223-260, ISSN: 0018-215-X 
multado con 150.000 pesetas, y Francisco Marcellán, quien, según Cantero, había llegado a asegurar lo siguiente: «Si tuviera que renegar de mi sacerdocio o de mi condición marxista, renegaría de la primera» ${ }^{75}$. Es más, el arzobispo aseguraba que había ayudado al diácono Ricardo Hernández, quien había sido sorprendido por la Policía repartiendo una propaganda ilegal en la que se atacaba al propio Cantero: había logrado sacar de la cárcel a él y otros detenidos por la misma razón a pesar de no encontrarse bajo la tutela del prelado por no poseer condición religiosa, y por ello la familia de este diácono había ido al arzobispado para agradecerle personalmente las gestiones hechas. Cantero había «redondeado» su actuación entregando a Hernández 4.000 pesetas para pagar la multa impuesta por el Tribunal de Orden Público.

Tras informar de manera tan profusa de cuál había sido su relación con el sector más rebelde de su clero, Pedro Cantero lanzaba a la Sagrada Congregación del Clero las siguientes interrogaciones:

«Podría seguir enumerando casos y casos, que no pueden ser negados por los sacerdotes del GRUPO SOLIDARIO, los cuales afirman que el cese dado al Cura de Fabara era expresión de que se quería anular la línea de pastoral seguida por ellos. ¿En qué fundamentan su afirmación? ¿Por qué interpretan tan arbitraria e injustamente un hecho tan sencillo como es el cambio de sacerdote en una parroquia? Supuestos los datos que anteceden ¿merece crédito su persuasión de que son objeto de persecución por mi parte, cuando lo que pienso es que habrá pecado de excesiva tolerancia para con ellos?» ${ }^{76}$.

De ahí que el prelado palentino no admitiera de ninguna manera esos calificativos que continuadamente escuchaba y que hacían que figurara como un obispo «conservador» y «político», mientras Delso era presentado, a su vez, como el representante de «(...) la noble causa de una pastoral social y de una iglesia en vanguardia ante la que muestran al Arzobispado como elemento represor» ${ }^{77}$. La realidad era, a juicio de Cantero, que el grupo de sacerdotes contestatarios había desarrollado desde el primer momento una actividad «febril» que ponía de manifiesto su deseo de confrontación con la cabeza de la diócesis.

\section{Actitud del Nuncio y los Obispos de Aragón en el proceso}

Pocas cosas quedaron sin comentar en el extenso informe de Cantero, y una de ellas fue el comportamiento tanto del Nuncio como de los prelados pertenecientes a la misma provincia eclesiástica que Cantero. Aunque el arzobispo pa-

75 Ibidem.

76 Ibidem.

77 Ibidem. 
rece querer exculpar a ambos, lo cierto es que se evidencia un claro tono de decepción, incluso de reproche, hacia todos ellos.

Comencemos por el Nuncio Dadaglio. Relataba Cantero a la Sagrada Congregación del Clero:

«Los días 12 y 13 de julio, el Sr. Nuncio Apostólico recibe una comisión de tres representantes del GRUPO. La versión pública que el GRUPO ha dado, por escrito, de esta visita es la siguiente: "en el desarrollo de la entrevista (el Sr. Nuncio) no defendió en ningún momento la postura de D. Pedro Cantero; no censuró la actitud de dimisión de los sacerdotes y aconsejó un último intento de diálogo con el Obispo antes de enviar recurso a Roma, cosa aceptada por él desde el principio». A esta manifestación escrita han acompañado alegaciones en público describiendo al Sr. Nuncio como animador de la causa por ellos defendida. A él han atribuido expresiones como las siguientes: "resistan dos años más (haciendo alusión al momento de mi jubilación)", "anoten todo y recurran a Roma", interpretando siempre estas frases ante grupos de fieles en el sentido de que el Sr. Nuncio "no les quitaba la razón y estaba con ellos".

Es evidente que yo no tengo nada que alegar contra la actitud del Sr. Nuncio. Me limito a señalar el hecho de cómo los componentes del GRUPO SOLIDARIO han querido aprovechar falsamente su personalidad a favor de su causa» ${ }^{78}$.

Por las palabras de Cantero, da la impresión de que se encontraba muy disgustado por el hecho de que Dadaglio hubiera querido recibir a estos sacerdotes, en lugar de apoyar con firmeza la autoridad del prelado palentino dentro de su diócesis. En todo caso, las palabras de Cantero hacia Dadaglio eran más benévolas que hacia sus compañeros de provincia eclesiástica, muy especialmente hacia el Obispo auxiliar y Administrador Apostólico «sede plena» de Huesca, el navarro Javier Osés, a quien ya hemos hecho referencia antes.

Estos obispos habían estado al tanto del conflicto desde prácticamente el inicio del mismo, una vez que el grupo de sacerdotes rebeldes les había hecho a estos el famoso documento de la Sagrada Congregación del Concilio de 29 de junio de 1950 que Cantero había adjuntado en la carta del 6 de julio y que les había hecho pensar que el Arzobispo de Zaragoza estaba dispuesto a excomulgar a estos sacerdotes. Al respecto afirmó Cantero en su informe:

«Nunca pasó por mi mente la idea de la excomunión. La fotocopia de la Nota no era sino un instrumento de reflexión para la conciencia de cada uno. Y así lo manifesté siempre que fui interrogado sobre el particular, y así lo confirmé a los Sres. Obispos de Tarazona y Huesca, y más tarde a una representación del grupo dimisionario compuesta por el P. Carmelo Martínez, D. Jesús Borao, D. Jesús Gil, D. Jesús Molinero y D. Wirberto Delso. Mi intención quedó tan clara que el mismo Obispo-Administrador apostólico de Huesca, Mons. Osés, afirmó: "ante esta aclaración, yo pienso que es un asunto interno de Zaragoza, y no quiero intervenir en él para nada”. Así opinó también el Sr. Obispo de Tarazona» ${ }^{79}$.

\footnotetext{
78 Ibidem.

79 Ibidem.
}

Hispania Sacra, Legalidad y conflictos, 58

117, enero-junio 2006, 223-260, ISSN: 0018-215-X 
Sin embargo, estas primeras informaciones dadas sobre la actuación de Javier Osés en el conflicto serían rápidamente matizadas por el propio Cantero hasta el punto de hacerle una muy severa crítica. Porque había llegado a los oídos del Arzobispo de Zaragoza que Osés, a través del sacerdote de su diócesis Luis García Torrecilla, años más tarde Vicario General de Huesca ${ }^{80}$ y, por tanto, «mano derecha» de Javier Osés, había solicitado a la Misioneras del Pilar su Casa de Ejercicios para que el Grupo Solidario pudiera reunirse ahí; es más, parece ser que se había reunido con ellos y que, durante la comida que compartió con ellos, les había animado a que persistieran en su actitud de rebeldía: «Manteneos firmes contra la injusticia», «ahora lo importante es que Vds. continúen con el pueblo y no deshagan el grupo», era lo que les había dicho, siempre según Cantero.

Eso eran, en todo caso, rumores. No obstante, él había podido comprobar en persona el comportamiento de Osés hacia este grupo, y así lo relató a la Sagrada Congregación del Clero:

«El día 6 de septiembre, a las once de la mañana comenzaba en mi Residencia Arzobispal la reunión a la que asistían los Obispos de Tarazona, Barbastro, Huesca, y también los entonces Vicarios Capitulares de Teruel y Albarracín, con D. Rafael Batalla, Secretario de la Conferencia Episcopal de Aragón, todos ellos citados por mí. Comenzada la reunión, solicité a los Sres. Obispos su consentimiento para que se personase la Comisión de Vicarios y Arciprestes. A esta propuesta el Sr. Administrador Apostólico de Huesca respondió que no se debía recibir en la reunión a esta Comisión si no se citaba a la vez a una representación de los sacerdotes dimisionarios. Yo hice notar que él había recibido ya muchas informaciones directas del Grupo...» ${ }^{81}$.

En ese sentido, Cantero había confirmado la falta de «solidaridad» de algunos de los obispos de su provincia eclesiástica cuando estos le comentaron su malestar por la aparición en la Agencia Cifra de un comunicado donde se decía que estos apoyaban al Arzobispo de Zaragoza en su decisión tomada con respecto al Párroco de Fabara. De nuevo Cantero volvía a lanzar su dedo acusatorio:

«Todos conocemos las tergiversaciones e inexactitudes de la prensa. Lo que sí es cierto es que los Sres. Obispos de Barbastro, Tarazona y Jaca me habían expresado confidencialmente su solidaridad y esto se había comentado privadamente en los sectores de la Curia. Además yo me pregunto: ¿por qué estos Sres. Obispos no han manifestado su disgusto cuando la Prensa ha publicado que apoyaban al GRUPO SOLIDARIO?» ${ }^{82}$.

${ }^{80}$ El anuncio de su nombramiento se hizo público a comienzos de 1981, permaneciendo en el cargo hasta finales de 1988, en que fue relevado por Agustín Catón. Véase al respecto Boletín Oficial del Obispado de Huesca, 1 y 2, enero-febrero de 1981, p. 25, y 1 y 2, enero-febrero de 1989, p. 17.

${ }^{81}$ AEESS R237 bis. Informe sobre la Instancia presentada a la Sagrada Congregación para el Clero por el Rvdo. Sacerdote D. Wirberto Delso Díez, ya citado.

82 Ibidem. 
Aunque concluía el informe sobre la actuación de sus compañeros de episcopado con sendos comentarios de apoyo de Francisco Álvarez Martínez y Javier Osés hacia su postura en el caso Fabara, lo cierto es que la Santa Sede tenía suficientemente información para pensar que en esta ocasión no se había producido la esperada expresión de corporativismo por parte de los obispos de la provincia eclesiástica aragonesa ${ }^{83}$.

\section{Conclusiones del Arzobispo de Zaragoza}

En realidad, el eco y la resonancia que todo este asunto había alcanzado no habían sorprendido excesivamente a Cantero, que lo veía lógico

«(...) por las características de este momento histórico que estamos viviendo en el que todo, eclesial y nacionalmente, se politiza y se hace bandera de cualquier acontecimiento con intereses partidistas» ${ }^{84}$.

Lo más importante era, para el Arzobispo de Zaragoza, que ya se habían producido, a la altura de comienzos de 1975, grietas dentro del grupo, pues hasta un total de ocho sacerdotes habían «desertado» del «Grupo Solidario» ${ }^{85}$. A pesar de ello, Cantero se mantenía inflexible en su posición, en la convicción de que no podían hacerse más cesiones, y centraba esta posición en la persona que había desatado toda la «tormenta», el sacerdote Wirberto Delso:

«No se puede aceptar que D. Wirberto permanezca en Fabara como Párroco, ni como Coadjutor ni siquiera como Adscrito.

No se puede aceptar la consulta a la comunidad cristiana de FABARA. ¿Cuál es la «comunidad cristiana» de FABARA?

No se puede aceptar confiar de nuevo a D. Wirberto otra parroquia, como primer responsable de la misma. Es viable darle el cargo de Coadjutor para que se una a un equipo sacerdotal de una Parroquia» 86 .

83 En ese sentido, Cantero aseguraba que un total de trece obispos se habían dirigido por escrito para mostrarle su apoyo, y que otros tantos lo habían hecho de manera verbal. Lo que seguía siendo un resultado pobre, teniendo en cuenta que el conjunto de todos ellos apenas superaba el $33 \%$ del conjunto del episcopado.

84 Ibidem.

85 Se trataba de José Antonio Pueyo, Jesús Borao, Manuel Liarte, Victorio Sevilla Luna, Francisco Chueca Sancho, José Luis Cuartero, José Luis Mur y Álvaro Lacaste, todos ellos Ecónomos en sus respectivas parroquias. Cantero comentaba sobre esta fractura del grupo rebelde: «Debe observarse que cada uno que se separa del Grupo provoca reacciones violentas de insultos y de acusación de traición». Véase al respecto Ibidem.

86 Ibidem. El arzobispo informaba de que había realizado dos ofertas concretas a Delso. La primera había sido nombrarle Coadjutor de la parroquia de la Madre de Dios de Begoña, que se encontraba ubicada en la zona obrera de Zaragoza; sobre esta no tenemos constancia, aunque no queremos decir con ello que Cantero estuviera faltando a la verdad. La segunda, por su parte, sí tenemos prueba docu-

Hispania Sacra, Legalidad y conflictos, 58

117, enero-junio 2006, 223-260, ISSN: 0018-215-X 
Desde esa perspectiva, Cantero tenía muy claro que dentro del Grupo Solidario, menos de una decena de personas eran realmente problemáticas. Pero con ellas sí que tenía muy claro lo que debía hacerse:

« ¿Se les puede dejar impunemente en su actitud con tan grave juicio para la Iglesia? ¿No debería desautorizarlos públicamente, dándoles las licencias ministeriales en esas parroquias en las que ellos se arrogan, por hechos consumados, una función que no tienen, frente a quien legítimamente la tiene? ¿No es de hecho un cisma?» ${ }^{87}$.

$\mathrm{Y}$ es que, si hacemos caso a las informaciones proporcionadas por Cantero, da la impresión de que el llamado caso Fabara había alcanzado unas cotas extraordinariamente graves. Porque el Arzobispo de Zaragoza afirmaba que había conexión entre estos sacerdotes y partidos políticos (PCE) y sindicatos (CC.OO.) ilegales, señalando que el líder de los comunistas, Santiago Carrillo, había escrito una carta de felicitación a Delso por la actitud de rebeldía mostrada. Era tal la tensión generada por el asunto que Cantero aseguraba haber recibido amenazas de muerte e insultos a través de anónimos atribuidos a la banda terrorista ETA, que poco más de un año antes, 20 de diciembre de 1973, había asesinado al propio Presidente del Gobierno Luis Carrero Blanco.

Cantero concluyó su informe recordando lo que había escrito a su momento al Nuncio: «Estas cosas, Señor Nuncio, me hacen sufrir mucho...». Y formuló una pregunta a la Sagrada Congregación del Clero cargada de dramatismo:

«¿QUÉ HA SUCEDIDO, PUES, DE UN HECHO EN CUYAS MOTIVACIONES E IMPLICACIONES SE VENTILABA LA INTEGRIDAD DE LA FE Y DE LAS COSTUMBRES, Y AFECTABA SOLAMENTE A UN SACERDOTE Y A UNA PARROQUIA, SE HA MANIPULADO PARA PRESENTARLO CALUMNIOSAMENTE COMO UNA CONDENACIÓN MÍA A UNA LÍNEA PASTORAL, QUE NO ES OTRA QUE LA DEL MOVIMIENTO DENOMINADO CRISTIANOS POR EL SOCIALIS$\mathrm{MO} ?{ }^{88}$.

\section{CONCLUSIONES}

El caso Fabara constituye uno de los hechos más graves de «contestación» dentro del clero en la última etapa del franquismo, pero no es el único. En mayor o menor medida, se produjo, en prácticamente todas las diócesis del país, porque en todas concurrían las mismas circunstancias: un marco político autori-

mental de ella, y es la coadjutoría de Alcañiz. Ambas, señalaba el prelado, habían sido rechazadas por Delso.

87 Ibidem.

88 Lo reproducimos exactamente como lo escribió Cantero en el informe, utilizando sus mismas mayúsculas. Véase al respecto Ibidem. 
tario, una sociedad en desarrollo, una politización de la fe y, a veces, hasta una evidente falta de vocación por el sacerdocio, que servía como plataforma de lucha ideológica gracias al privilegiado marco que proporcionaba el Concordato de 1953.

En ese sentido, el conflicto desatado entre Cantero y el llamado «Grupo Solidario» realmente no tuvo vencedores ni vencidos. Cantero logró su objetivo de que Delso no volviera nunca a ejercer como Párroco en Fabara, pero su autoridad fue ampliamente cuestionada. En ello tuvo mucho que ver la falta de apoyo de la Santa Sede, cuya apuesta por el aggionarmento chocaba frontalmente con la visión típicamente nacionalcatólica de Cantero, un obispo cuyo tiempo había pasado y que no entendía o no aceptaba los nuevos vientos que amainaban en la Iglesia española. No obstante, la persistencia en su actitud de no ceder ante el Grupo Solidario le proporcionó la victoria no sólo de no volver a Delso en Fabara, sino también la reintegración, antes o después, de muchos de los sacerdotes rebeldes en el organigrama de la diócesis ${ }^{89}$. Fue, en definitiva, toda una época de la Iglesia española que no ha vuelto a repetirse y que dejó atrás un importante rastro de polémica y, por supuesto, también de debate historiográfico.

\footnotetext{
89 Jesús Borao es, en la actualidad, Párroco de Villanueva de Gállego; Luis Bel, Párroco de Santa Anastasia y de Bárdenas del Caudillo; José Luis Cuartero, Párroco de Luceni; Francisco Chueca, Párroco de San José Artesano; Manuel Liarte, Párroco de Nuestra Señora del Portillo; José Antonio Pueyo, Párroco de Gallur; Victorio Sevilla, Párroco de San Lamberto y Consiliario de la HOAC; José Luis Mur, Vicario Parroquial y encargado de Corpus Christi; o Luis Betés, Adscrito a Nuestra Señora del Rosario de (Zaragoza capital). También siguen en activo como sacerdotes de la diócesis Isidro Jesús Cabello o Porfirio Pascual, y alguno ya está jubilado, como Jesús Molinero. Otros, por su parte, dejaron el sacerdocio y tienen relación con la política, como Álvaro Lacasta, que es miembro, exactamente Vicepresidente $1 .^{\circ}$, por el Partido Socialista Obrero Español -(PSOE), Consejo de la Comarca de Cinco Villas (Zaragoza)—, o no tenemos información sobre ellos, como el mencionado diácono Ricardo Hernández o el sacerdote Mariano García Cerrada, pero sí de su hermano, Antonio, que es Canónigo.

Véase al respecto http://www.arzobispadodezaragoza.org/home.htm.

Hispania Sacra, Legalidad y conflictos, 58

117, enero-junio 2006, 223-260, ISSN: 0018-215-X
} 